\title{
HISTOLOGICAL STUDY AND IMMUNOHISTOCHEMICAL EXPRESSION OF INDUCIBLE NITRIC OXIDE SYNTHASE AND VASCULAR ENDOTHELIAL GROWTH FACTOR IN SKIN WOUND HEALING AND ITS APPLICATION FOR FORENSIC WOUND AGE DETERMINATION
}

\author{
Fatma E. Agha1, Mona A.R. Salem², Rehab A.A. Hasan ${ }^{2}$, Amal A.M. Ahmed 1
}

${ }^{1}$ Forensic Medicine and Clinical Toxicology Department, Faculty of Medicine for Girls, AlAzhar University, Cairo, Egypt

${ }^{2}$ Histology Department, Faculty of Medicine for Girls, Al-Azhar University, Cairo, Egypt

\section{ABSTRACT}

Wound healing examination is one of the most important aspects of the forensic pathology to estimate wound age. Chronological histopathological alterations characterizing the different phases of wound healing can be applied to wound age determination. Recently immunohistochemical studies are used for cutaneous wound age determination. Therefore, the aim of this work was to investigate the morphological changes as a result of ante-mortem (A/M) and post mortem (P/M) incisional skin wound and to evaluate the immunohistochemical expression of inducible nitric oxide synthase (iNOS) and vascular endothelial growth factor (VEGF) for wound age estimation. Thirty five adult male albino rats were divided into seven groups (five rats each). group1 (G1) five rats was used as a control to study the normal skin structure. Twenty five rats were wounded; one $\mathrm{cm}$ length and full thickness skin incision was made on the back of each animal. The animals were then divided into five equal groups. Skin biopsies were taken 6 hours (G2), 1 day (G3), 3 days (G4), 6 days (G5) and 10 days (G6) after incision. G7 represented P/M group. Skin biopsies were processed for histological and immunohistochemical studies. Morphometric and statistical analysis were done. Different degrees of wound healing signs (re-epithelization, granulation tissue formation, cellular infiltration and new collagen formation) could be detected with L/M examination of H\&E and masson trichrome stained sections of $\mathrm{A} / \mathrm{M}$ wounded groups. In $\mathrm{P} / \mathrm{M}$ wound, no signs of wound healing could be detected. Immunohistochemical study of all groups revealed that iNOS expression markedly increased after 6 hours and peaked at 1day after incision. After 3days and 6days, it is still highly significant increased but less than 6hours after incision and peaked again after 10days to be nearly of its expression at 6hours after incision. iNOS was not expressed in $\mathrm{P} / \mathrm{M}$ wound. VEGF expression gradually increased with increase post wounding time, it peaked at 10 days after incision but was not expressed in normal intact skin, 6 hours after incision and in $\mathrm{P} / \mathrm{M}$ wound. There was highly significant correlation between optical density means of iNOS / VEGF and optical density means of VEGF/mean area $\%$ of collagen fibers. We can conclude that, time dependent expression of both iNOS, VEGF proteins and area $\%$ of collagen fibers suggested that they would be useful markers for the determination of cutaneous wound age assisted by histological changes during different stages of wound healing.

Keywords: Nitric oxide synthase, Vascular endothelial growth factor, Cutaneous wound age estimation, Immunohistochemistry, Forensic histology. 


\section{INTRODUCTION}

Skin wound age and wound healing examination is one of the most important aspects of the forensic pathology (Nogami et al., 2010). During the process of wound examination, to evaluate the causal relationship between death and any wounds, forensic pathologists are always required to discriminate ante-mortem wounds from postmortem damage. Moreover, when the wound is vital, it is necessary to determine how long before death it was sustained (Kondo, 2007).

Skin wound healing is a complex process in which there is repair of injured epidermal and dermal tissues (Desmouliere et al., 2005). It starts immediately after injury and consists of three phases: inflammation, proliferation, and maturation. These phases proceed with complicated but well-organized interaction between various tissues and cells (Ishida $\boldsymbol{e t}$ al., 2004; 2006 \& 2008).

Historically, Walcher, (1930) and Orsos, (1935) first discuss, based on their practical experiences without scientific evidence, that the determination of wound vitality or wound age was indispensable in forensic practice. For example, chronological histopathological alterations characterizing the different phases of wound healing can be applied to wound age determination. In particular, upon injury, neutrophils are recruited at the injury site, followed by macrophages in-accordance with the post-infliction interval. Raekallio, (1976) one of the most famous forensic scientists, tried to resolve the problem scientifically. He investigated the activity of several enzymes at a wound site by enzyme histochemistry. Some years later, Berg \& Bonte (1971) evaluated the levels of serotonin and histamine at the wound edges, which gave evidence of vital phenomena. Thereafter, with the advance of immunohistochemistry, the application of immunohistochemical techniques opened up a new field of wound age investigation by forensic pathologists, Eisenmenger et al., (1988) and Oehmichen, (1990). Immunohistochemical studies on IL-8, MCP-1, MIP-1 $\alpha$ (Kondo et al., 2002) and melanocyte migration into human scar tissue (Dressler $\boldsymbol{e t}$ al., 2001) were performed, and the mRNA dynamics of inflammatory cytokines, such as IL-1 $\alpha$, IL-1 $\beta$, IL-6, TNF $\alpha$ (Sato \& Ohshima, 2000) and IL-10 (Sato et al., 1999) were examined for cutaneous wound age determination. Various biological substances, such as growth factors, cytokines and adhesion molecules are involved in each phase of the wound healing process (Ishida et al., 2004, 2006 \& 2008).

Inflammation, reepithelialization, and granulation tissue formation are driven by a complex mixture of growth factors and cytokines, which are released into the area of injury. Besides these factors, evidence is emerging for an important role of small molecules in wound repair (Frank et al., 1999). Nitric oxide (NO) is an important messenger molecule that is involved in physiological and pathophysiological processes in numerous organ systems and involved in the regulation of apoptosis. A variety of different cell types are able to release NO. Endogenous NO is synthesized from L-arginine by a family of nitric oxide synthase (NOS) isoenzyms: the neuronal (nNOS), the inducible (iNOS), and the endothelial (eNOS) isoform. NO has been shown to play important roles in normal skin biology and also diseased skin. Expression of iNOS has been initially reported in keratinocytes from normal skin. Studies on skin tissue have also demonstrated a key function of NO in the process of cutaneous wound healing. As iNOS-deficient mice suffered from a delay in wound repair, and inhibition of iNOS 
during healing resulted in a markedly reduced re-epithelialization (Boissel $\boldsymbol{e t}$ al., 2004 and Zhao et al., 2009).

Vascular endothelial growth factor (VEGF) is a disulfide linked dimeric glycoprotein of about $40 \mathrm{kDa}$ (kilo dalton) that enhances vascular permeability, induces chemotaxis and activation of monocytes/macrophages, and promotes growth of vascular endothelial cells (Iijima et al., 1996). VEGF has been reported to be involved in vascularization. This factor has also been implicated in the wound healing process. In skin wound healing, angiogenesis is a crucial event for formation of new granulation tissue in the proliferative phase (Mori et al., 2002; Lin $\boldsymbol{e t}$ al., 2003 and Ishida et al., 2004). VEGF is a highly potent angiogenic factor that can regulate and increase microvasculature (Tao et al., 2007).

Expression of VEGF has been demonstrated in proliferating keratinocytes at the wound edge during cutaneous repair, revealing keratinocytes as an important source of VEGF production within this process (Frank et al., 1999).

The aim of this study is to investigate the histological changes of incisional skin wound and to evaluate the immunohistochemical expression of iNOS and VEGF in wound age estimation.

\section{MATERIAL AND METHODS}

In this study 35 adult male albino rats were used. The animals were aged approximately 12 weeks old and weighted about 225 to $250 \mathrm{gm}$. They were housed in plastic cages and left for one week prior to the experiment. Commercial rat chew and water were allowed. Five animals represented the control group (G1) were anesthetized by ether inhalation, $2 \times 1 \mathrm{~cm}$ skin biopsies from their back were taken after hair shaving to study the structure of intact normal skin. The skin of the back of 25 rats represented the wounded ante-mortem groups was shaved then it was swabbed with $70 \%$ alcohol and one cm length, full thickness skin incision was made. The incision was covered with sterile cotton gauze and the animals were housed in individual cages and allowed to recover. Wound specimens were taken from (G2) 6 hours after incision. In G3, wound specimens were taken 1day (24 hours) after incision. G4, wound specimens were taken 3days (72 hours) after incision. G5, wound specimens were taken 6days (144 hours) after incision. G6, wound specimens were taken 10days (240 hours) after incision. These skin specimens were dissected out by using a sterile surgical blade with a half $\mathrm{cm}$ from the surrounding non-wounded skin. G7 represented P/M wound group in which the last 5 animals were killed by cervical dislocation then the wound was made after 30 minutes post mortem and the wound specimens were excised 1 hour after death.

\section{Histological technique:}

Skin specimens were fixed using $10 \%$ neutral buffered formaldehyde. After proper fixation, the specimens were dehydrated, cleared in xylol, impregnated and then embedded in paraffin wax. 5 microns sections were cut using rotatory microtome. Skin sections were stained with H\&E stain (Bancroft \& Gamble, 2002) and Masson trichrome stain (Drury \& Wallington, 1980), then examined under light microscope. 


\section{Immunohistochemical techniques:}

Skin sections were deparaffinized and rehydrated. Endogenous peroxidase activity was blocked with $5 \% \mathrm{H}_{2} \mathrm{O}_{2}$ in absolute methanol for $10 \mathrm{~min}$ at room temperature. Then, the sections were rinsed in phosphate buffered saline (PBS). Sections were incubated with primary antibodies against iNOS and VEGF. Protein expression level was evaluated using a streptavidin biotin peroxidase kit. Sections were stained with diaminobenzidine (DAB) as chromogen for iNOS and VEGF detection and then counterstained with hematoxylin (Pitlovanciv et al., 2013).

\section{Morphometric study:}

The optical density of positive staining of (iNOS, VEGF) was measured using a computerized image system composed of a Leica Qwin 500 image analyser which is connected to a Leica microscope. Five randomly selected high power microscopic fields within the wound area were examined to measure the optical density of iNOS (Wang et al., 2013), VEGF (Zhuang et al., 2013) and area percentage of collagen fibers (masson trichrome stain) (Mohamad et al., 2011).

\section{Statistical analysis:}

Data evaluation was expressed as means \pm Standard Deviation (SD) and analysis was performed using SPSS program. The one way ANOVA (F) test was used for data analysis between all groups. Also, the correlation coefficient " $r$ "test was used to correlate between two variables. $\mathrm{P}<0.05$ was considered statistically significant, $\mathrm{P}<0.01$ was considered statistically high significant and $\mathrm{P}<0.001$ was considered statistically very high significant (Zhao et al.,

2009).

\section{RESULTS:}

\section{Histological results:}

Examination of sections of control unwounded skin (G1) revealed the normal structure of the thin skin of adult male albino rats. The skin appeared formed of thin epidermis and dermis. The epidermis was formed of stratified squamous keratinized epithelium resting on a wavy basement membrane. This epithelium was formed of basal layer, intermediate layers and superficial layer. The dermal layer contained fine and coarse irregular collagen fibers and skin appendages (hair follicles \& sebaceous gland). The hypodermis was present deep to the dermis. (Fig.1-A, A', B \& Fig.2-A)

Naked eye examination of the wound 6hours post wounding (G2) revealed that it was covered by blood clot. Light microscopic examination of skin sections 6hours post wounding, showed retraction of the two edges of the wound. The keratin scales covering the epidermis near the wound edge were fragmented. The epidermis appeared of irregular thickness. The epidermal cells were highly compressed in some areas. Collagen fibers in the dermis appeared distorted and discontinuous but no obvious increase in collagen fibers in wound region if compared to control group. The hair follicles were distorted in comparison to control (Fig.1-C, C' and Fig.2-B). Microscopic examination of skin sections, 1day post wounding (G3), revealed that the space 
between the wound edges was covered by a scap. The keratin and the epidermal layer were completely disappeared under the scap. The epithelial cells of the epidermis near wound edge appeared irregularly arranged, their cytoplasm was vacuolated with small deeply stained nuclei. The dermal papillae disappeared. The collagen fibers at the wound edge showed slight increase in thickness if compared with control skin. Hair follicles at the wound edge appeared distorted, compared with control. Numerous mononuclear inflammatory cells could be detected. (Fig.1-D, E, F \& Fig.2-C).

Examination of skin 3days post wounding (G4), showed signs of early wound healing. A large scap covering the wound surface could be detected. A newly formed epithelial layer (reepithelization) began to appear under the scap, covering surface of the wound. This epithelium had variable thickness with flattening of dermo-epidermal junction. The epithelial cells appeared irregularly arranged and distorted. Their cytoplasm was vacuolated with small darkly stained nuclei. Granulation tissue filled the wound space. This granulation tissue was formed of mononuclear cellular infiltration, some newly formed collagen fibers and many dilated blood vessels. The collagen fibers appeared thick at the wound edge in comparison to control. Epithelial tongue formed of aggregations of epithelial cells could be observed invading the granulation tissue under the newly formed epithelium (Fig.1-G, H \& Fig.2-D).

Sections of 6days post wounding (G5), showed that keratinocytes in the newly formed epithelium appeared irregularly arranged with vacuolated cytoplasm and darkly stained small nuclei. Granulation tissue filled the gap between the wound edges under the newly formed epithelium appeared markedly infiltrated with mononuclear cells, many dilated blood vessels and irregular newly formed collagen fibers. The collagen fibers appeared thick at the wound edge in comparison to control. Epithelial tongues formed of aggregations of epithelial cells could be observed invading the dermis under the newly formed epithelium (Fig.1-I \& Fig.2-E).

Skin sections 10days post wounding (G6) revealed complete closure of the wound with a newly formed layer of epithelium and disappearance of the scab. The epithelial cells appeared more or less normal. The dermo-epidermal junction was flattened with loss of the dermal papillae and skin appendages. The underlying granulation tissue was replaced by new dermal tissue. This dermis contained dense, interrupted and irregular newly formed collagen fibers with many dilated blood vessels and numerous mononuclear inflammatory cells. The collagen fibers appeared thick at the wound edge in comparison to control (Fig.1-J \& Fig.2-F).

Examination of P/M group (G7) revealed that the signs of wound healing were absent at the wound region. Some autolytic changes began to appear in the form of distorted hair follicles and some interrupted collagen fibers. No apparent increase in collagen fibers could be detected (Fig.1-K \& Fig.2-G).

\section{Immunohistochemical, morphometric and statistical results:}

iNOS expression appeared as dark brown cytoplasmic stain in positive reaction. Weak iNOS expression was detected in the normal rat skin. It was mainly detected in the epidermal cells and hair follicles cells (Fig.3). There was moderate expression in skin of 6 hours post wounding sections. Examination of 1day, 3days, 6days and 10days post wounding specimens, revealed strong positive cytoplasmic immunoreactions in epidermal cells and hair follicles cells. 
VEGF expression was mainly localized within the cytoplasm of keratinocytes and appeared as dark brown stain. Examination of VEGF immunohistochemical stain (Fig.4) demonstrated negative cytoplasmic expression in control skin and 6 hours post wounding. Moderate immunoreactions 1 day after incision could be observed. While strong positive cytoplasmic immunoreactions 3days, 6days and 10days after incision could be detected. Neither iNOS nor VEGF were expressed in the nucleus of the keratinocytes. iNOS and VEGF expressions were found negative in the postmortem specimens.

Statistical study concerning iNOS optical density means revealed that, the highest mean was recorded among 1day post wounding group (86.6 \pm 3.9$)$ followed by 10days post wounding group (78.6 \pm 4.5$)$, these findings were very high statistical significant $(\mathrm{P}<0.001)$. The least mean was in control skin $(9.2 \pm 1.9)$. These findings were very high statistical significant $(\mathrm{P}<0.001)$. The optical density means of iNOS showed gradual increase in 6 hours post wounding group (49.4 \pm 3.1$)$ followed by 6days post wounding group $(68.9 \pm 1.9)$ and finally 3 days post wounding group (69.9 \pm 2.9$)$. All these findings were very high statistical significant $(\mathrm{P}<0.001)$. The optical density mean of iNOS in P/M wound was (0.0) [Table 1, Chart 1 \& 2]

Studying the VEGF optical density means in all experimental groups revealed that the highest mean was recorded in 10days after incision group $(75.6 \pm 1.1)$. The least mean was observed 1day post wounding (55 \pm 2.2 ). The optical density means of VEGF were in 3 days post wounding (64.4 \pm 1.1$)$ and 6days post wounding (69.8 \pm 1.5$)$. All these findings were very high statistical significant $(\mathrm{P}<0.001)$. The optical density means of VEGF in control skin, 6hours post wounding, and P/M wound were (0.0). [Table 1, Chart 1 \& 2]

When comparing the mean area of collagen fibers in all groups, the highest mean was recorded in G6 (70.4 \pm 2.8$)$ and the least mean was in G7 (48.8 \pm 3.1$)$ followed by G1 (49.6 \pm 1.5$)$. The mean of area $\%$ of collagen fibers in other groups revealed gradual increase from G2

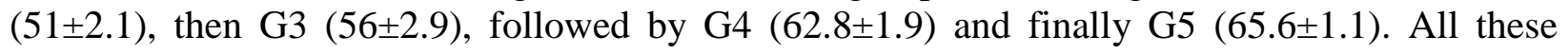
findings were very high statistical significant $(\mathrm{P}<0.001)$. [Table 1 , Chart 1 \& 2]

There was very high statistical significant correlation between optical density means of iNOS / VEGF and between optical density means of VEGF / means of area \% of collagen fibers according to correlation coefficient " $r$ " $(\mathrm{P}<0.001)$. [Table 2] 
Table (1): Mean \pm SD of optical density of iNOS, VEGF and mean \pm SD area $\%$ of collagen fibers

\begin{tabular}{|c|c|c|c|}
\hline Variable & & & \\
\hline & $\begin{array}{c}\text { Optical density } \\
\text { means of INOS } \\
\mathbf{X}^{-} \pm \text {SD }\end{array}$ & $\begin{array}{c}\text { Optical density } \\
\text { means of VEGF } \\
\mathbf{X}^{-} \pm \text {SD }\end{array}$ & $\begin{array}{c}\text { Mean of area \% of } \\
\text { collagen fibers } \\
\mathbf{X}^{-} \pm \text {SD }\end{array}$ \\
\hline G1 & $9.2 \pm 1.9$ & 0.0 & $49.6 \pm 1.5$ \\
\hline G2 & $49.4 \pm 3.1$ & 0.0 & $51 \pm 2.1$ \\
\hline G3 & $86.6 \pm 3.9$ & $55 \pm 2.2$ & $56 \pm 2.9$ \\
\hline G4 & $69.9 \pm 2.9$ & $64.4 \pm 1.1$ & $62.8 \pm 1.9$ \\
\hline G5 & $68.9 \pm 1.9$ & $69.8 \pm 1.5$ & $65.6 \pm 1.1$ \\
\hline G6 & $78.6 \pm 4.5$ & $75.6 \pm 1.1$ & $70.4 \pm 2.8$ \\
\hline G7 & 0.0 & 0.0 & $48.8 \pm 3.1$ \\
\hline One way Anova'F" test & 975.7 & 249.73 & 68.26 \\
\hline P & $<0.001$ & $<0.001$ & $<0.001$ \\
\hline
\end{tabular}

"G= Group

iNOS = inducible nitric oxide synthase

$\mathrm{VEGF}=$ vascular indothelial growth factor

$\mathrm{P}<0.001=$ very high statistical significant

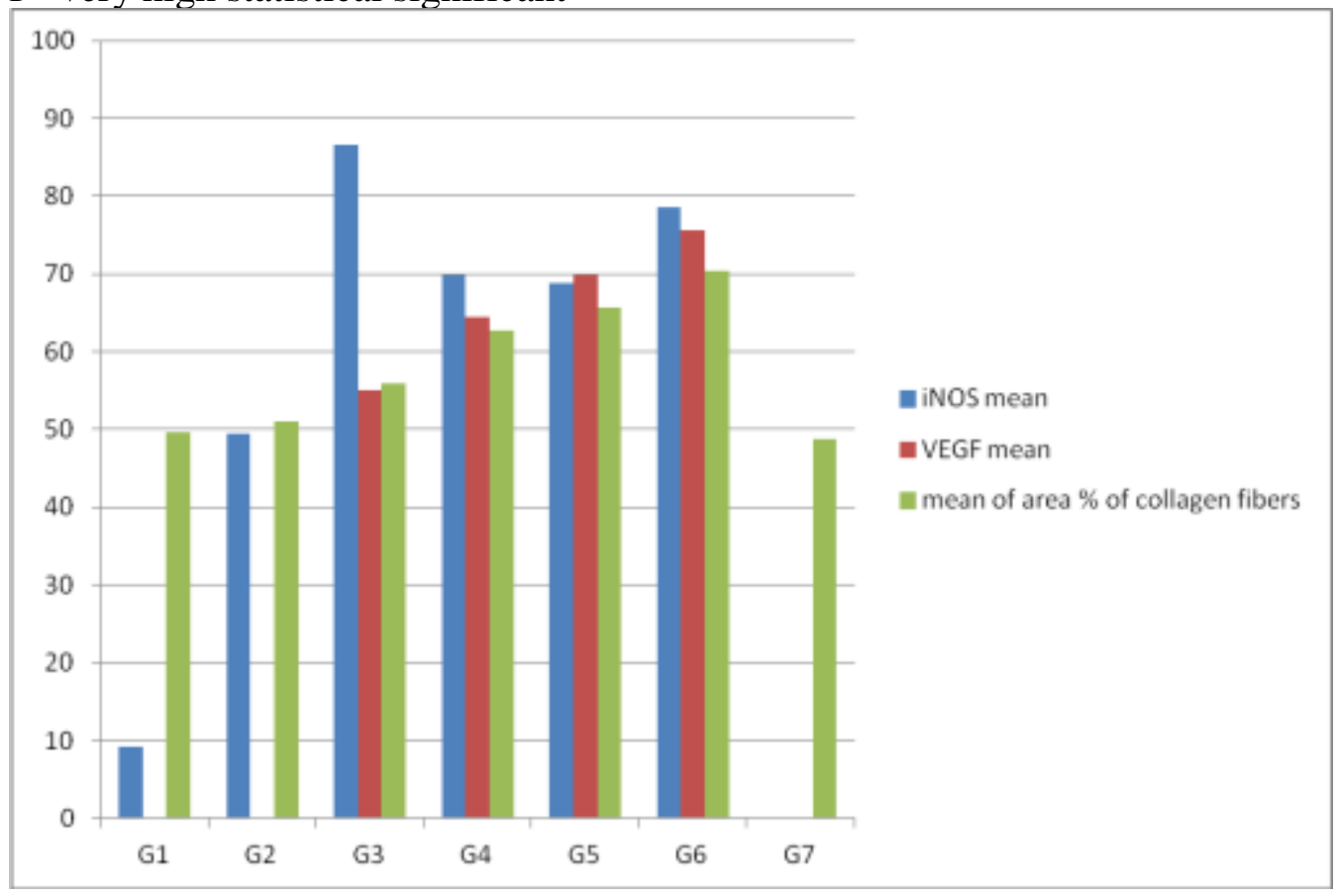

Chart (1): Means of optical density of iNOS, VEGF and area \% of collagen fibers

Vertical line represents means of optical density of iNOS, VEGF and means of area $\%$ of collagen fibers.

Horizontal line represents the different groups. 


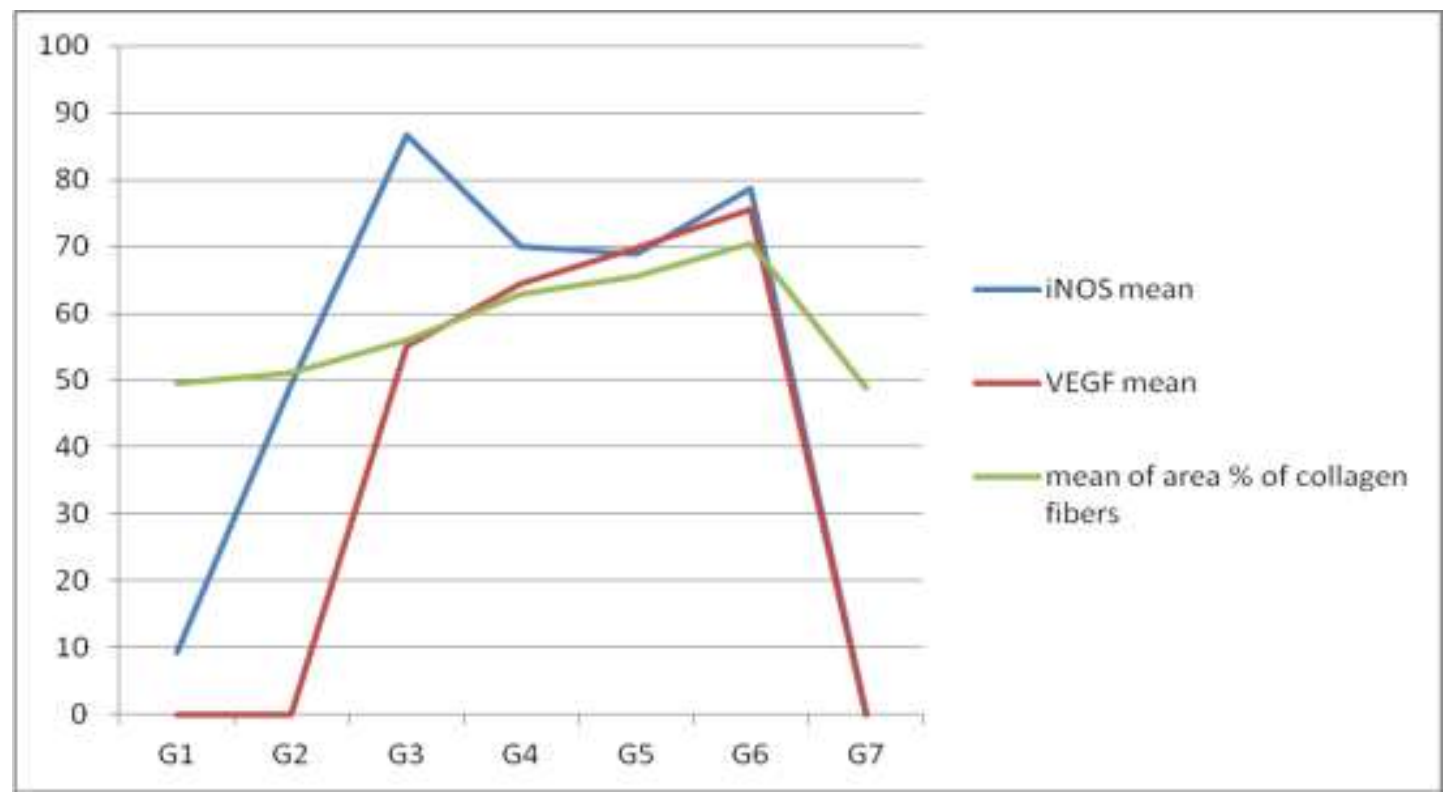

Chart (2): Means of optical density of iNOS, VEGF and area \% of collagen fibers

- $\quad$ Vertical line represents means of optical density of iNOS, VEGF and means of area $\%$ of collagen fibers.

Horizontal line represents the different groups.

Table (2): correlation Coefficient " $r$ " between optical density means of VEGF, iNOS and mean of area $\%$ of collagen fibers.

\begin{tabular}{|c|r|r|r|r|}
\hline & \multicolumn{2}{|c|}{ INOS } & \multicolumn{2}{c|}{ Area\% } \\
\cline { 2 - 5 } Study group & \multicolumn{1}{|c|}{ r } & P & \multicolumn{1}{c|}{ r } & P \\
\hline G3 & 0.998 & $<0.001$ & 0.988 & $<0.001$ \\
\hline G4 & 0.9461 & $<0.001$ & 0.998 & $<0.001$ \\
\hline G5 & 0.651 & $<0.001$ & 0.975 & $<0.001$ \\
\hline G6 & 0.731 & $<0.001$ & 0.998 & $<0.001$ \\
\hline
\end{tabular}

r= correlation coefficient

$P<0.001=$ very high statistical significant 


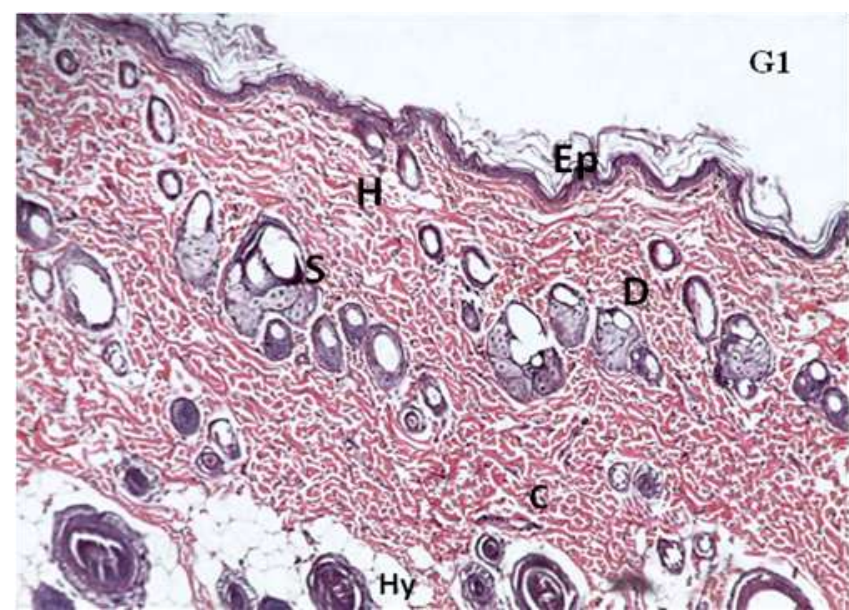

Fig. (1-A) A photomicrograph of control skin section of adult male albino rat (G1), showing that the thin skin is composed of thin epidermis (Ep) and underlying dermis (D). The epidermis is formed of stratified squamous epithelium resting on a wavy basement membrane and covered by scales of keratin. Fine and coarse irregular collagen fibers $(\mathrm{C})$ can be seen in the dermis. Also, nuclei of C.T cells, hair follicles $(\mathrm{H})$ and sebaceous glands $(\mathrm{S})$ can be observed. A fatty C.T layer hypodermis (Hy) is clearly seen. [H\&Ex100]

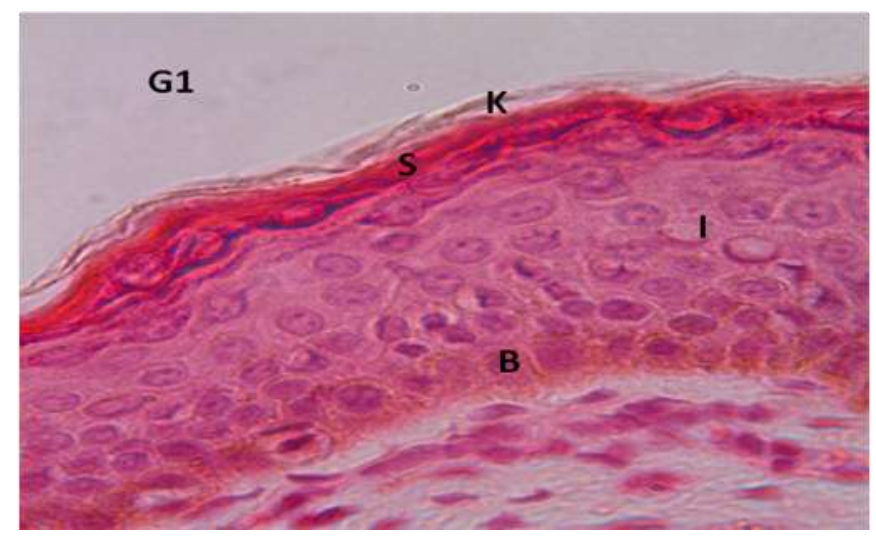

Fig. (1-B) A photomicrograph of control skin section of adult male albino rat (G1), showing that the epidermis of thin skin is composed of stratified squamous epithelium, covered by scales of keratin (K). This epithelium is formed of basal layer (B), intermediate layers (I) and superficial layer (S). [H\&Ex400]

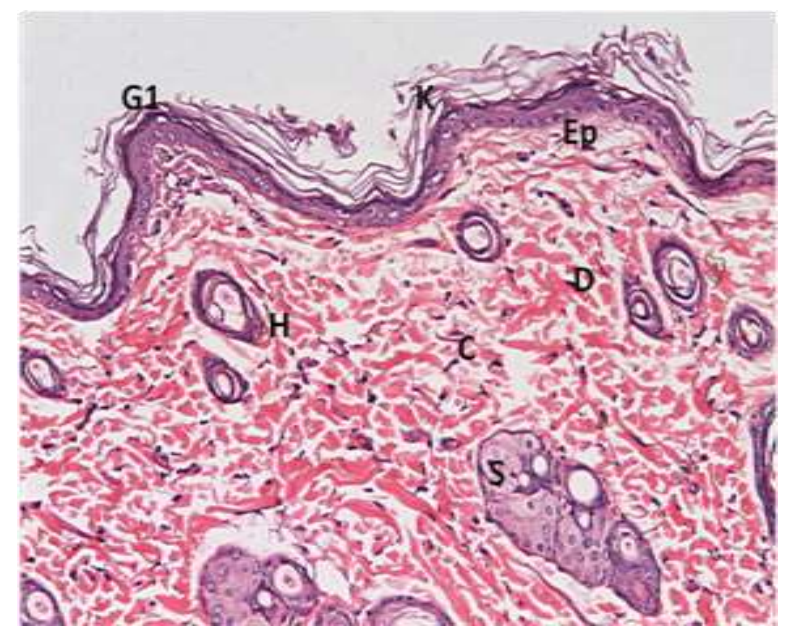

Fig. (1-A') A photomicrograph of control skin of section of adult male albino rat (G1), showing that the thin skin is composed of thin epidermis (Ep) and underlying dermis (D). The epidermis is formed of stratified squamous epithelium resting on a wavy basement membrane and covered by scales of keratin $(\mathrm{K})$. Fine and coarse irregular collagen fibers $(C)$ can be seen in the dermis. Also, nuclei of connective tissue cells, hair follicles $(\mathrm{H})$ and sebaceous glands (S) can be observed. [H\&Ex100]

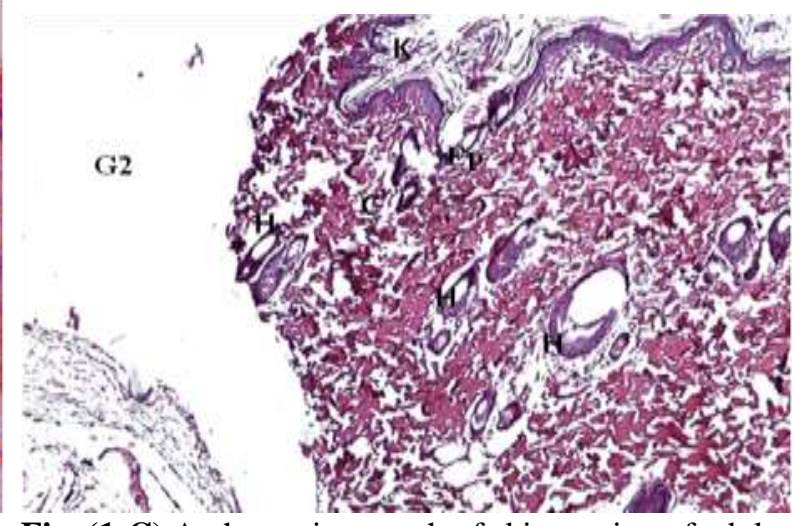

Fig. (1-C) A photomicrograph of skin section of adult male albino rat 6hours post wounding (G2) showing one edge of the wound because the wound edges are widely separated. The keratin scales covering the epidermis near the wound edge are fragmented $(\mathrm{K})$. The epidermis (Ep) appears of irregular thickness and the epidermal cells are highly compressed in some areas. Collagen fibers (C) in the dermis appear distorted and discontinuous and the hair follicles are distorted (H). [H\&Ex100] 


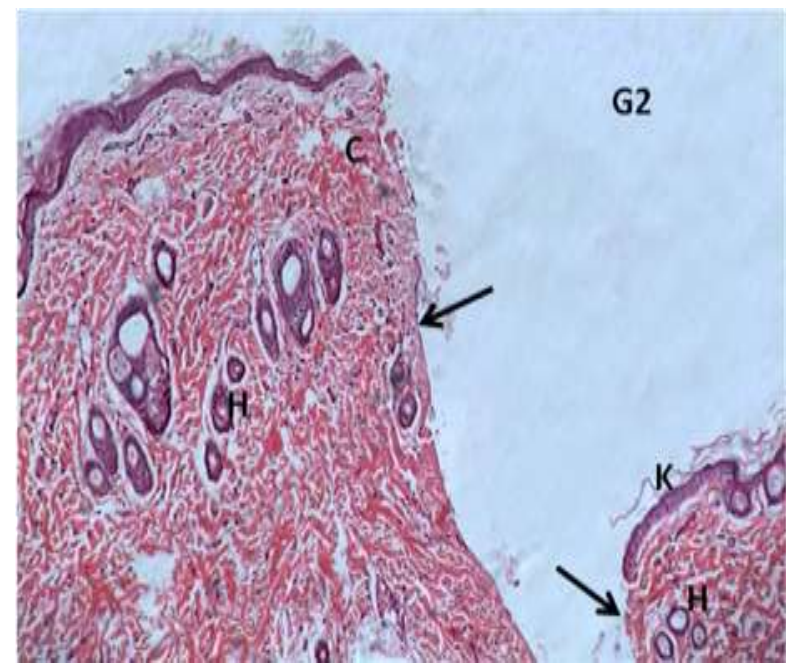

Fig. (1-C') A photomicrograph of skin section of adult male albino rat 6hours post wounding (G2), showing the two edges of the wound are widely separated and retracted (arrows). Notice, keratin (K), collagen fibers (C) and hair follicles $(\mathrm{H})$. [H\&Ex100]

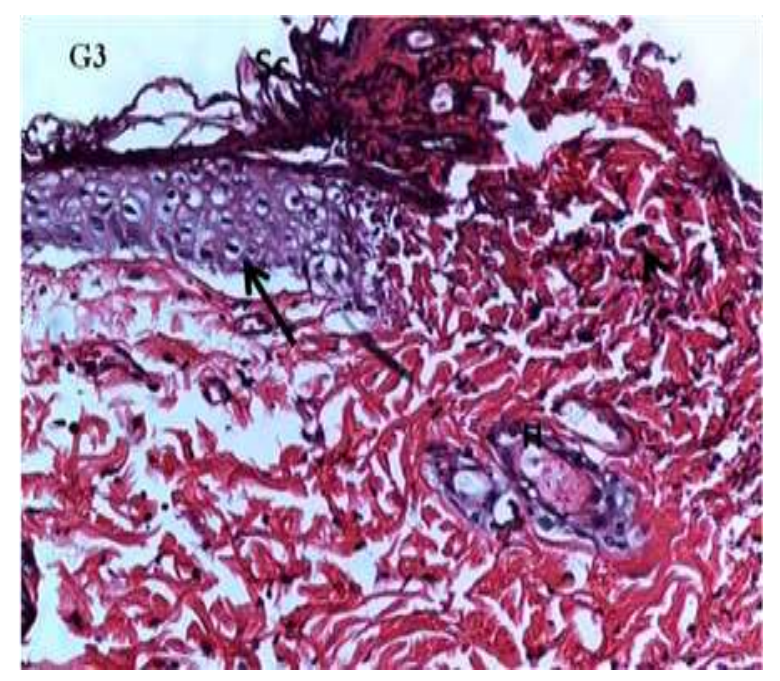

Fig. (1-E) A photomicrograph of skin section of adult male albino rat, 1day post wounding (G3), showing that the epithelium at the wound edge is interrupted and the epithelial cells appear irregularly arranged with disappearance of dermal papillae (arrow). Their cytoplasm is vacuolated with small eccentric darkly stained nuclei. Mononuclear inflammatory cells can be detected (arrow head). Notice, collagen fibers (C) and hair follicle (H). [H\&Ex200]

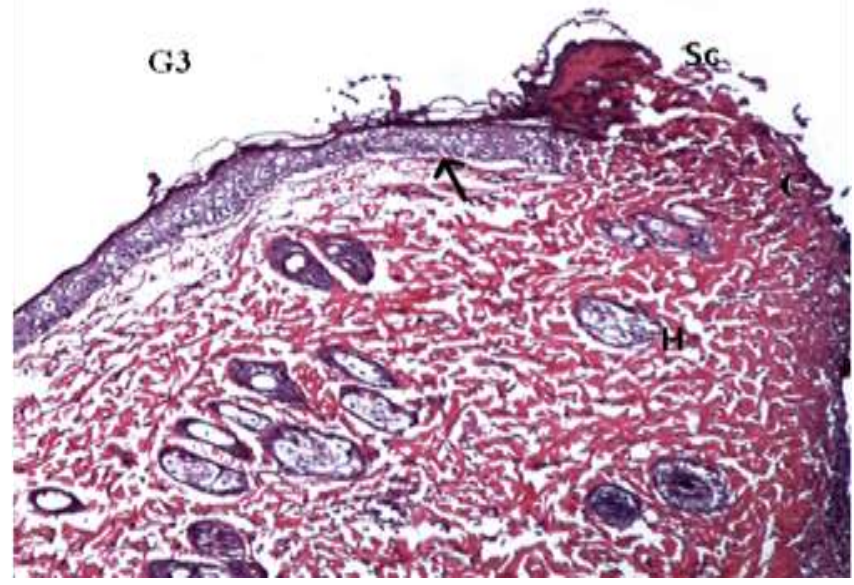

Fig. (1-D) A photomicrograph of skin section of adult male albino rat, 1day post wounding (G3), showing one edge of the wound, the wound surface is covered by scap (Sc). The dermal papillae are disappeared (arrow).The collagen fibers (C) appear slightly thicker in comparison to the normal. Hair follicles $(\mathrm{H})$ appear distorted.

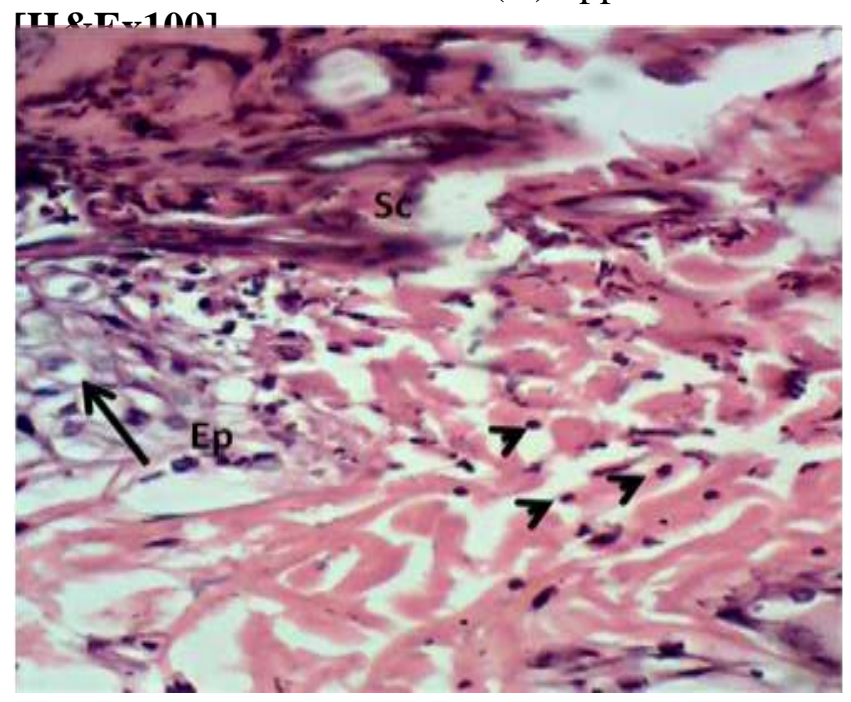

Fig. (1-F) A photomicrograph of skin section of adult male albino rat 1day post wounding (G3), showing that the epithelium at the wound edge is interrupted and the epithelial cells appear irregularly arranged (Ep). Their cytoplasm is vacuolated with small eccentric darkly stained nuclei (arrow). Mononuclear inflammatory cells can be detected (arrow heads). [H\&Ex400] 


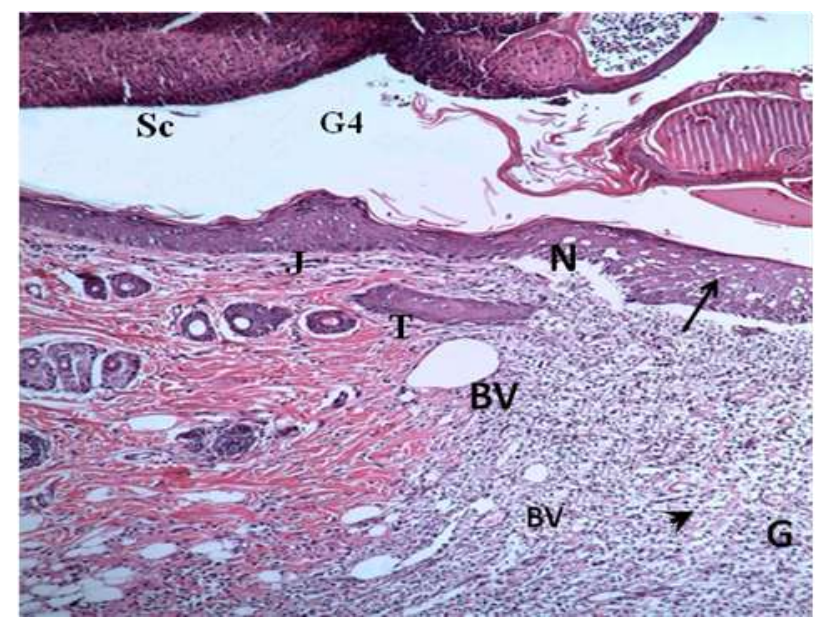

Fig. (1-G) A photomicrograph of skin section of adult male albino rat, which represent 3 days post wounding (G4), showing large scap (Sc) covering wound surface. A newly formed epithelial layer, re-epithelization $(\mathrm{N})$ is formed covering surface of the wound. This epithelium has variable thickness with flattening of dermo-epidermal junction (J). The epithelial cells (arrow) appear irregularly arranged, distorted, with vacuolated cytoplasm and small darkly stained nuclei. Granulation tissue (G) fills the wound space. This granulation tissue is formed of mononuclear cellular infiltration, some newly formed collagen fibers (arrow head) and many dilated blood vessels (BV). Epithelial tongue can be observed under the newly formed epithelium (T). [H\&Ex100]

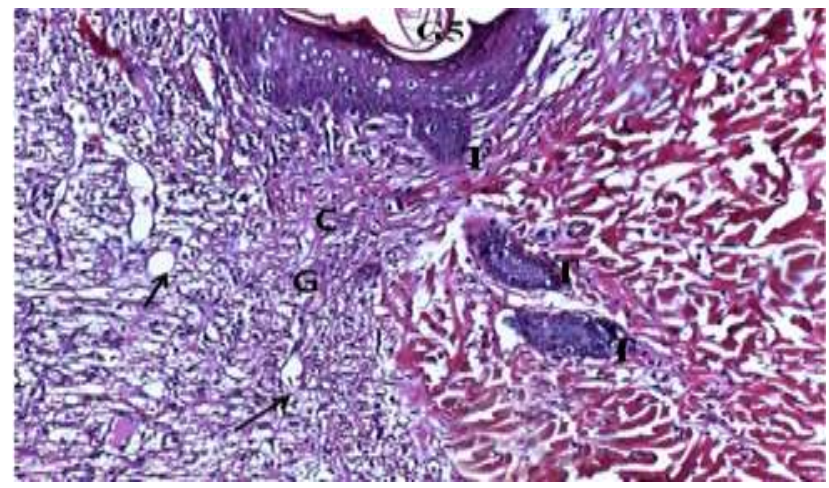

Fig. (1-I) A photomicrograph of skin section of adult male albino rat, 6 days post wounding (G5) showing keratinocytes in the newly formed epithelium appear irregularly arranged. Their cytoplasm is vacuolated with small darkly stained nuclei. The granulation tissue $(\mathrm{G})$ contains irregular newly formed collagen fibers $(\mathrm{C})$ with many blood vessels (arrows) and extensive mononuclear inflammatory cells. Epithelial tongues can be observed under the newly formed epithelium (T). [H\&Ex200]

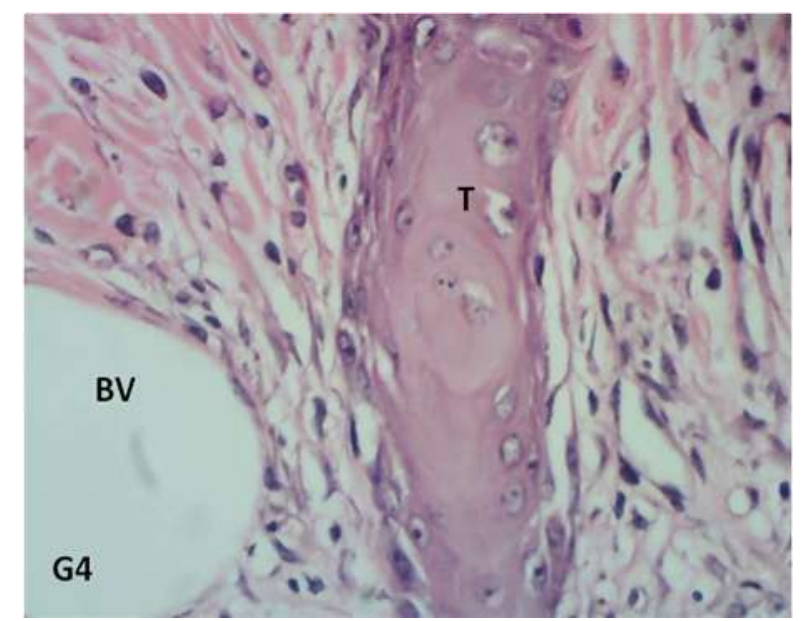

Fig. (1-H) A photomicrograph of skin section which represent 3 days post wounding (G4), showing the epithelial tongue (T) and dilated blood vessel (BV). [H\&Ex400]

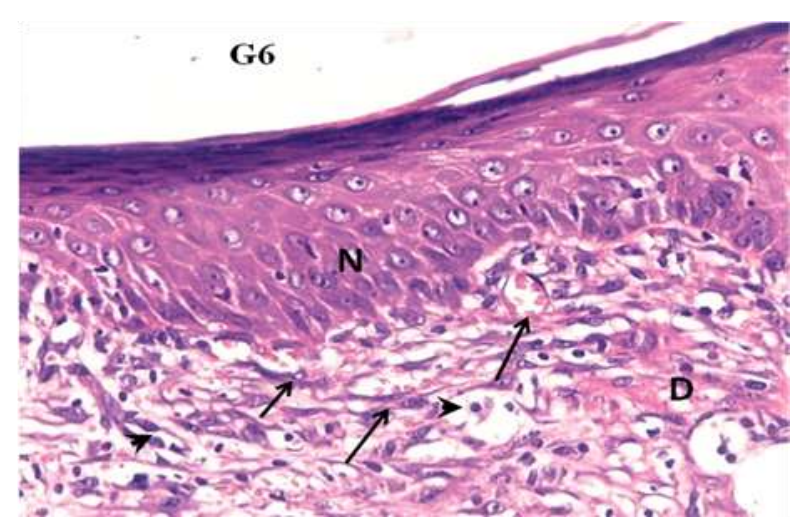

Fig. (1-J) A photomicrograph of skin section of adult male albino rat, 10 days post wounding (G6), showing that the wound space is completely closed with newly formed epithelium $(\mathrm{N})$ with complete disappearance of scab. The epithelial cells appeared more or less normal. The dermo-epidermal junction was flattened with loss of the dermal papillae. The dermis (D) contained numerous blood vessels (arrows), mononuclear inflammatory cells, most probably fibroblasts and lymphocytes (arrow heads). No skin appendages can be detected. [H\&Ex400] 


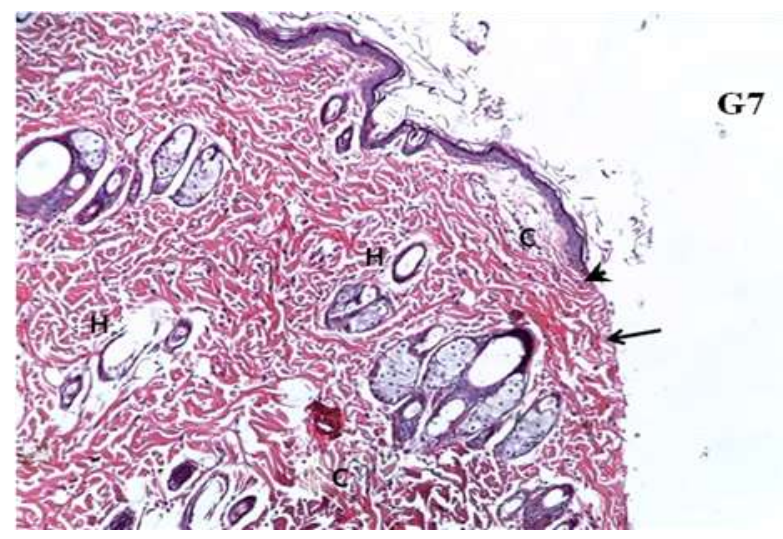

Fig. (1-K) A photomicrograph of skin section of adult male albino rat which represents $\mathrm{P} / \mathrm{M}$ wound (G7), showing one edge of the wound. Signs of wound healing are absent at the wound region (arrow).The epidermis is interrupted at the wound region (arrow head). Some collagen fibers $(\mathrm{C})$ and hair follicles $(\mathrm{H})$ appear abnormal in wound region. [H\&Ex100]

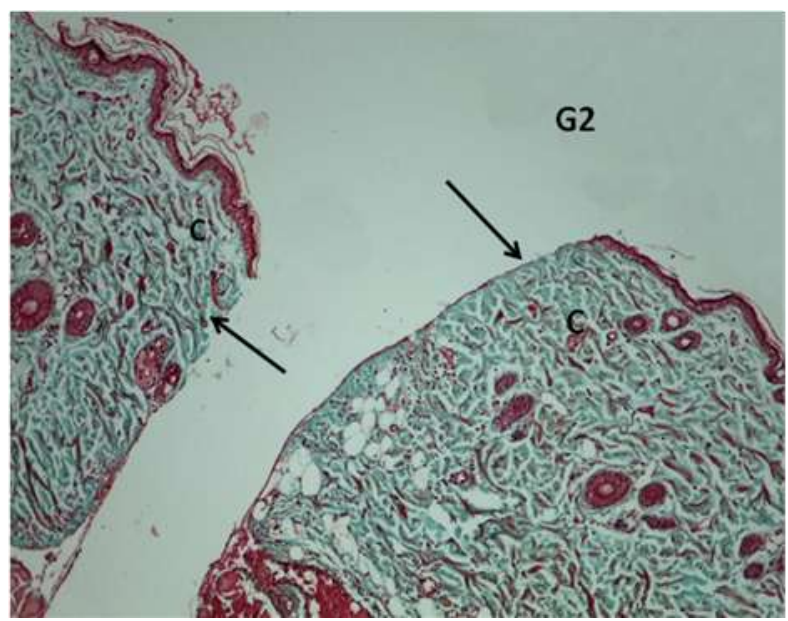

Fig. (2-B) A photomicrograph of a section in the skin of adult male albino rat which represent 6hours post wounding (G2) showing no apparent increase in collagen fibers (C) in the wound area in comparison to control. Edges of the wound appear retracted (arrows). [Masson trichrome x100]

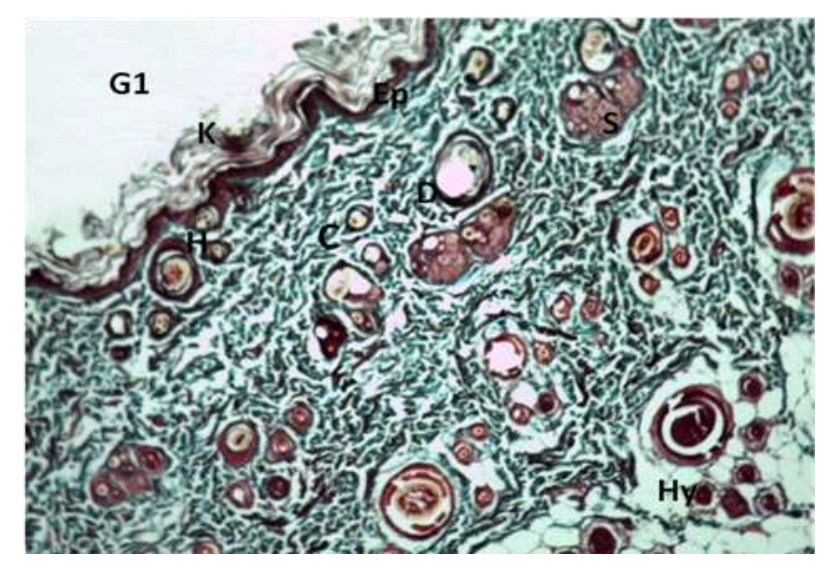

Fig. (2-A) A photomicrograph of a section in the skin of adult male albino rat which represent unwounded control group (G1) showing, different layers of skin; epidermis (Ep) and dermis (D). Hypodermis (Hy) could be observed. Keratin (K) could be seen. Collagen fibers (C) of the dermis which stained green could be seen. Notice, hair follicle $(\mathrm{H})$ and sebaceous gland $(\mathrm{S})$. [Masson trichrome $\mathrm{x100}$ ]

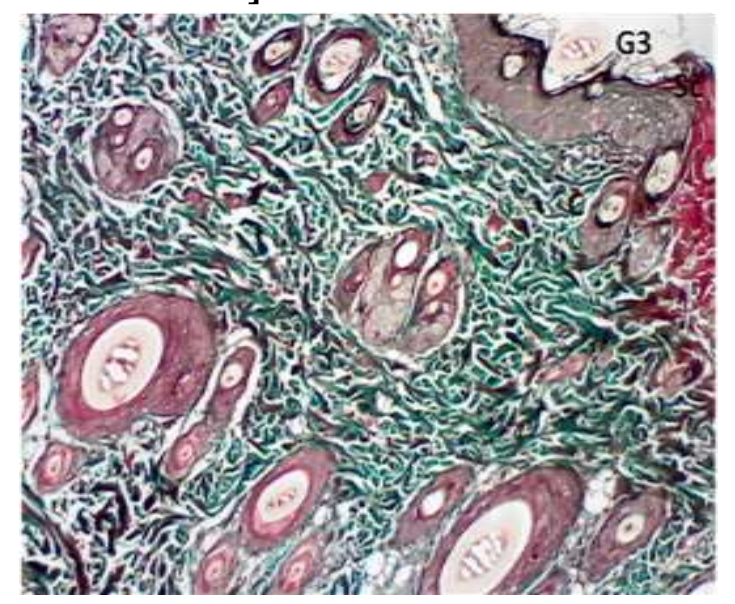

Fig. (2-C) A photomicrograph of a section in the skin of adult male albino rat which represents 1day post wounding (G3) showing slight increase in collagen fibers $(C)$ in wound region in comparison to control. Scab $(\mathrm{Sc})$ at the wound edge can be detected. [Masson trichrome $x 100$ ] 


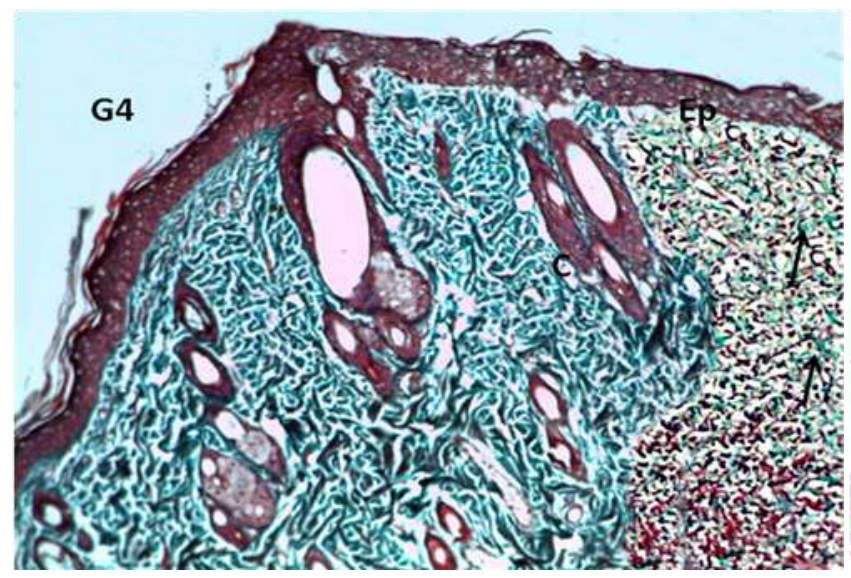

Fig. (2-D) A photomicrograph of a skin section of adult male albino rat, which represents 3 days post wounding (G4) showing that the collagen fibers become thicker at the wound edge (C) in comparison to control. Newly formed collagen fibers appear in wound area (arrows). The newly formed epithelium (Ep) can be seen. [Masson trichrome x100]

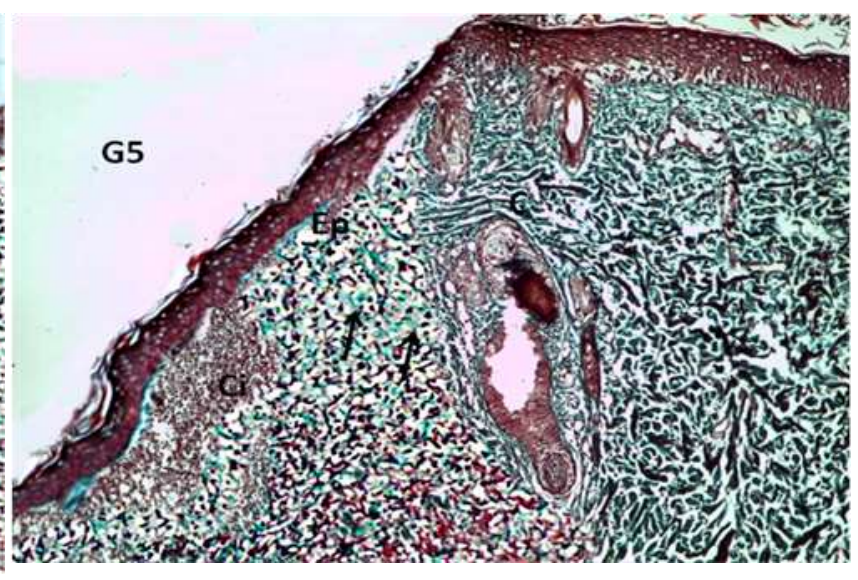

Fig. (2-E) A photomicrograph of a skin section of adult male albino rat, which represents 6 days post wounding (G5) showing that collagen fibers become thicker at the wound edge (C) in comparison to control. Newly formed collagen fibers appear in wound area (arrows). The newly formed epithelium (Ep) can be seen. Notice, area of cellular infiltration (Ci). [Masson trichrome x100]

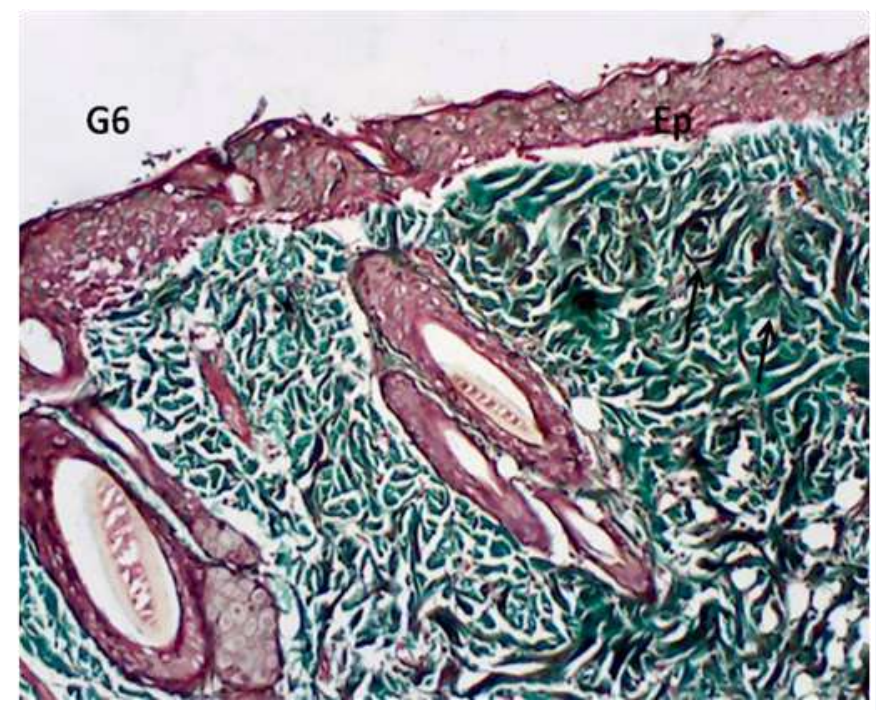

G7

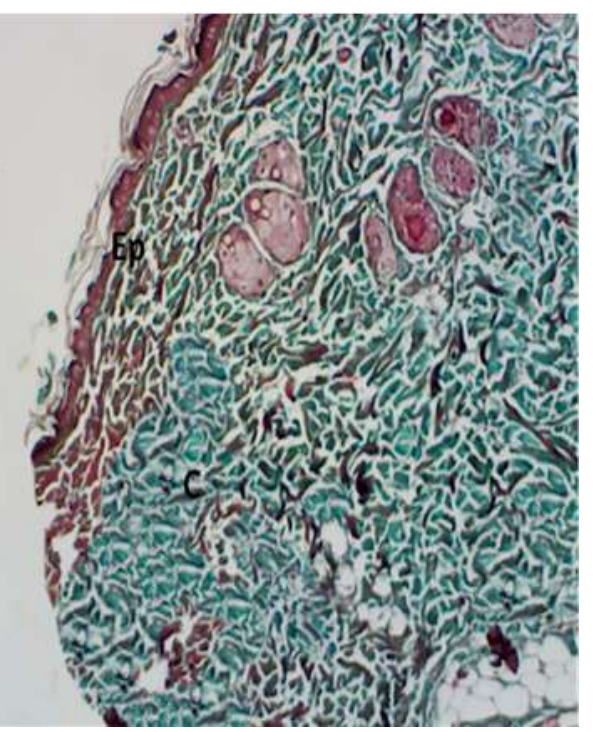

Fig. (2-F) A photomicrograph of a skin section of adult male albino rat, which represents 10 days post wounding (G6) showing, marked increase in collagen fibers in wound area (arrows) in comparison to control. The newly formed epithelium (Ep) can be seen. [Masson trichrome x100]
Fig. (2-G) A photomicrograph of a skin section of adult male albino rat, which represents P/M wound (G7) showing, no obvious increase in collagen fibers (C) in comparison to control unwounded skin. [Masson trichrome x100] 


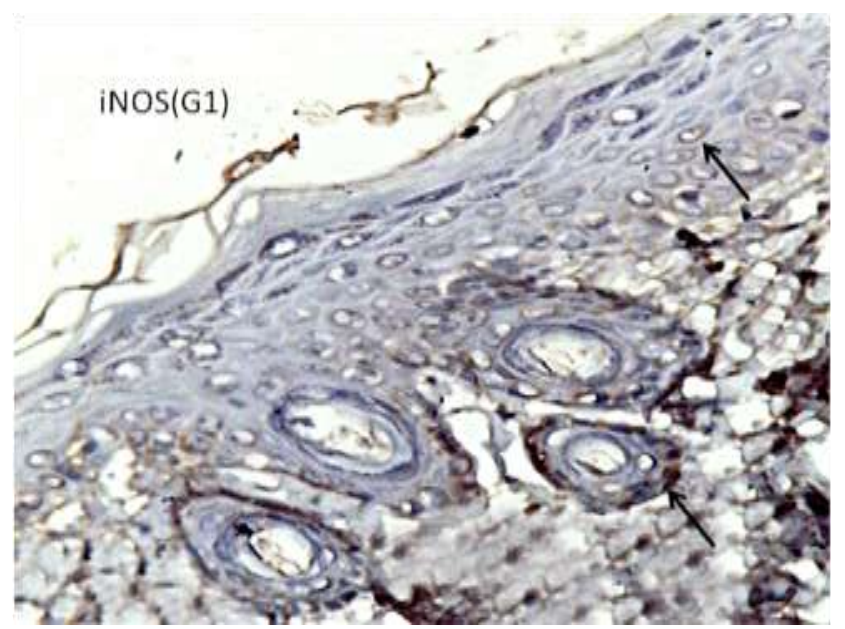

Fig. (3-A) A photomicrograph of a section in the unwounded control skin (G1) of adult male albino rat, showing weak cytoplasmic immunoreaction for iNOS in epidermal cells and hair follicles cells (arrows). [Avidin-biotin peroxidase stain with $H x$ counter stain $x 400]$

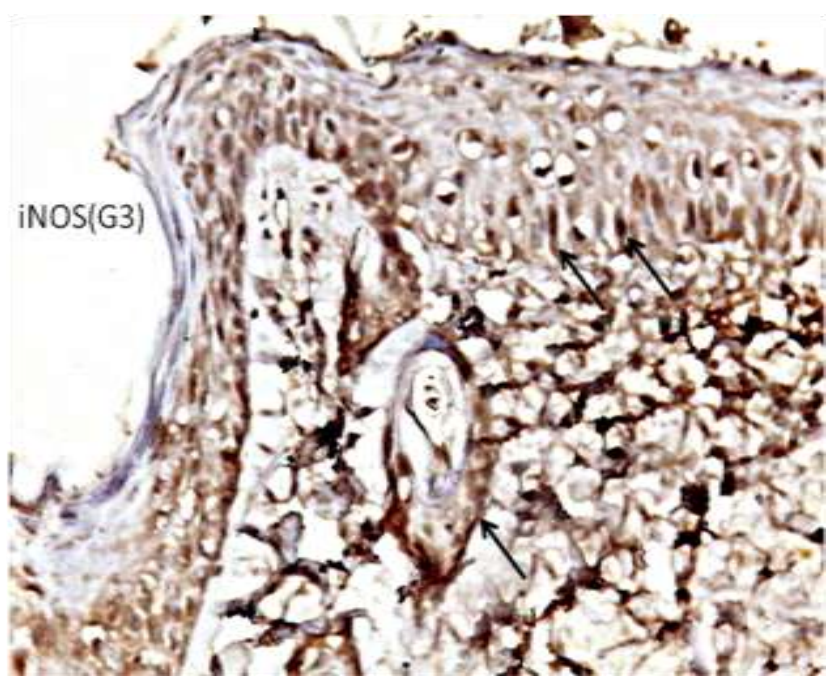

Fig. (3-C) A photomicrograph of a section in the skin of adult male albino rat 1day post wounding (G3) showing, strong positive cytoplasmic immunoreaction for iNOS in epidermal cells and hair follicle cells (arrows). [Avidin-biotin peroxidase stain with $\mathrm{Hx}$ counter stain $x 400$ ]

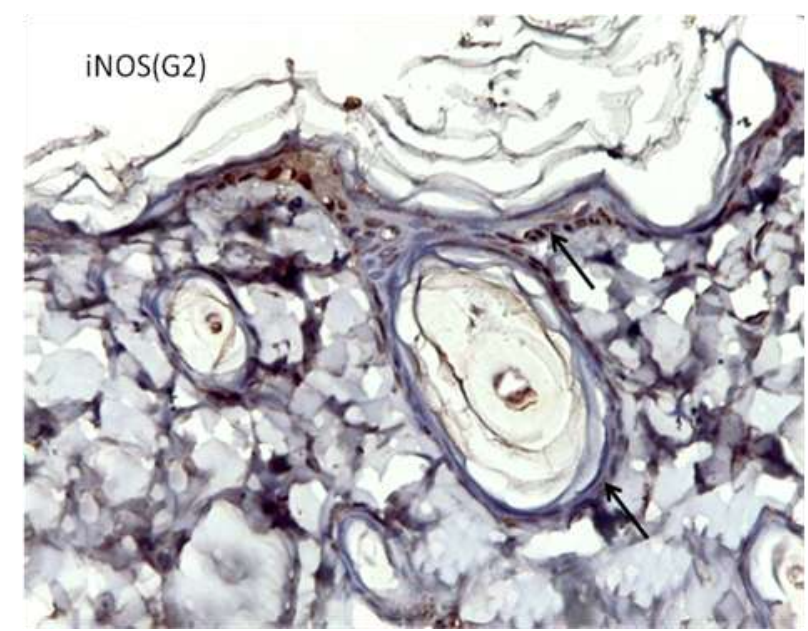

Fig. (3-B) A photomicrograph of a section in the skin of adult male albino rat 6hours post wounding (G2) showing, moderate cytoplasmic immunoreaction for iNOS in epidermal cells and hair follicles (arrows). [Avidin-biotin peroxidase stain with $\mathbf{H x}$ counter stain $x 400]$

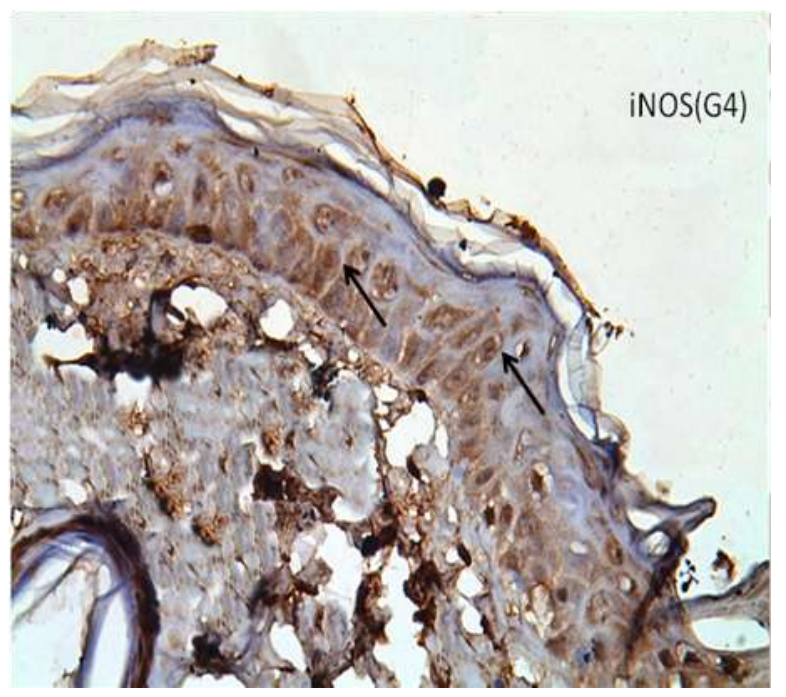

Fig. (3-D) A photomicrograph of a skin section of adult male albino rat 3 days post wounding (G4) showing, strong positive cytoplasmic immunoreaction for iNOS in epidermal cells (arrows). [Avidin-biotin peroxidase stain with $\mathrm{Hx}$ counter stain $\mathrm{x400}$ ] 


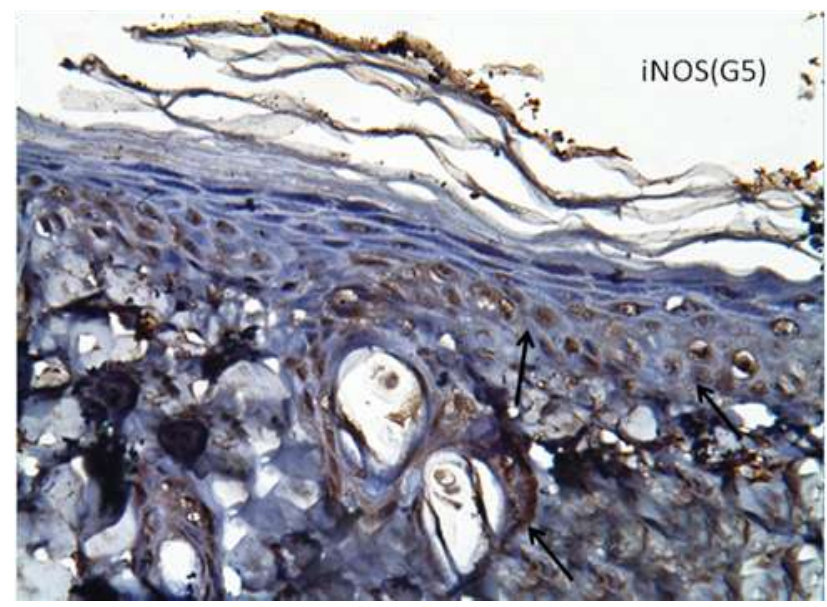

Fig. (3-E) A photomicrograph of a skin section of adult male albino rat 6 days post wounding (G5) showing strong positive cytoplasmic immunoreaction for iNOS in epidermal cells and hair follicles (arrows). [Avidin-biotin peroxidase stain with $H x$ counter stain $x 400$ ]

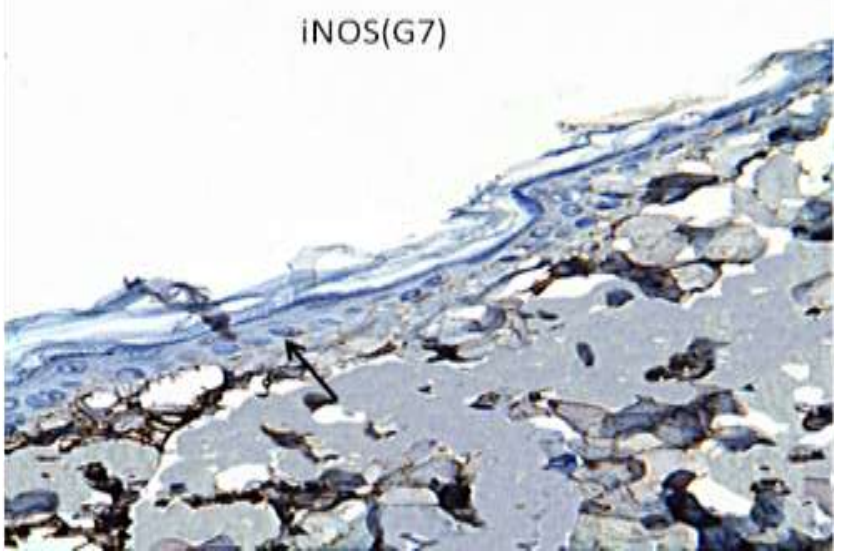

Fig. (3-G) A photomicrograph of of adult male albino rat skin section of P/M wound (G7) showing, negative immunoreaction for iNOS in the area of the wound (arrow). [Avidin-biotin peroxidase stain with $H x$ counter stain $x 400]$

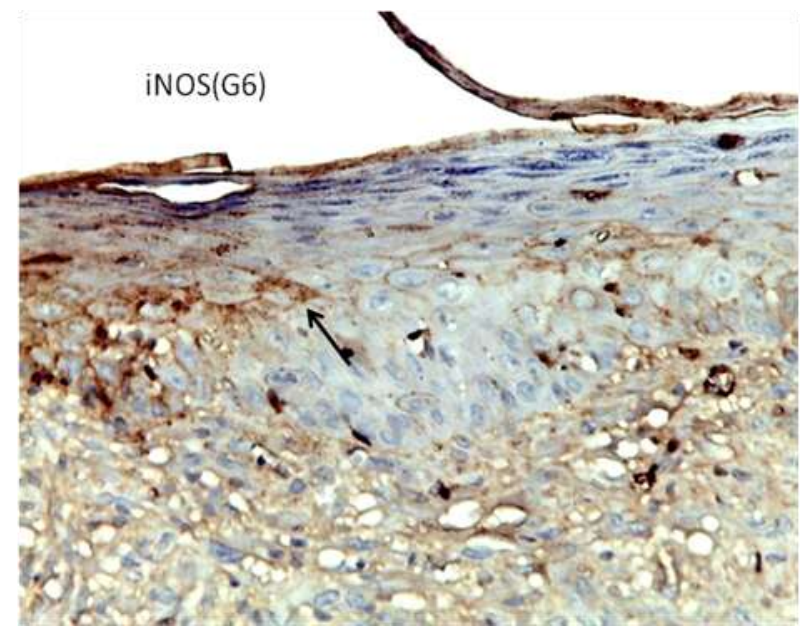

Fig. (3-F) A photomicrograph of a skin section of adult male albino rat which represent 10 days post wounding (G6) showing, strong positive cytoplasmic immunoreaction for iNOS in epidermal cells in the area of the wound (arrow). [Avidinbiotin peroxidase stain with $\mathrm{Hx}$ counter stain $\mathrm{x} 400$ ]

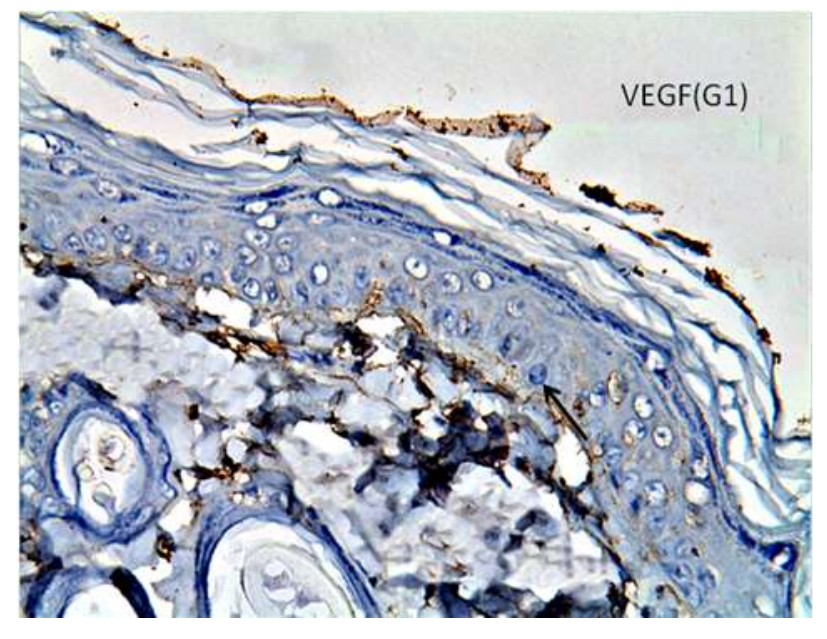

Fig. (4-A) A photomicrograph of a section in the unwounded control skin (G1) of adult male albino rat showing, negative cytoplasmic immunoreaction for VEGF (arrow). [Avidinbiotin peroxidase stain with $\mathrm{Hx}$ counter stain $\mathrm{x} 400$ ] 


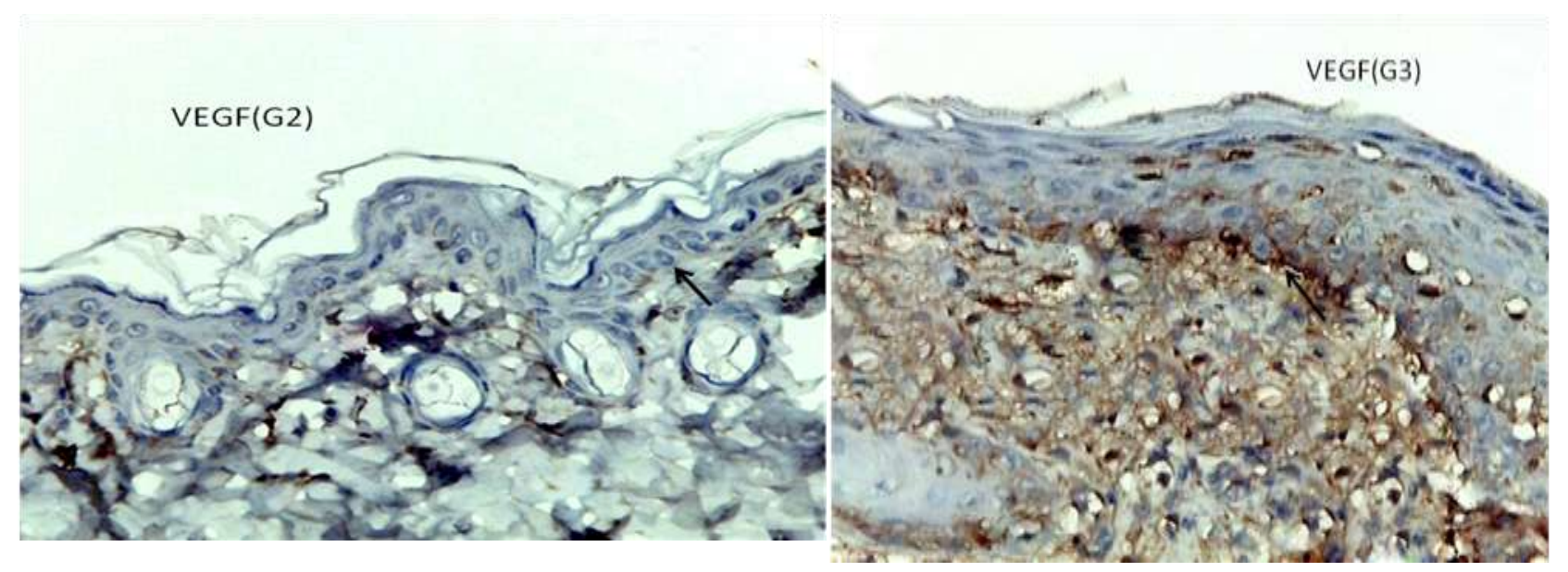

Fig.(4-B) A photomicrograph of a section in the skin of adult male albino rat 6hours post wounding (G2) showing, negative cytoplasmic immunoreaction for VEGF in epidermis (arrow). [Avidin-biotin peroxidase stain with $\mathrm{Hx}$ counter stain $x 400$ ]

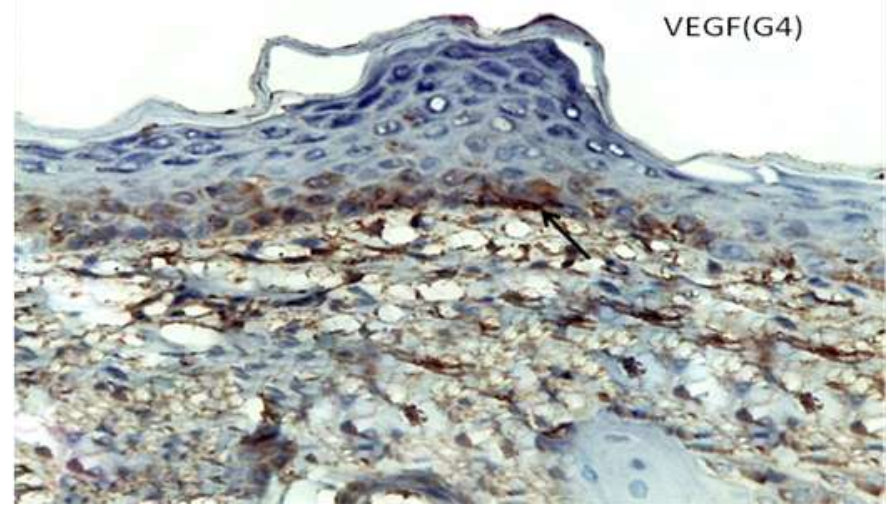

Fig.(4-D) A photomicrograph of a skin section of adult male albino rat, 3 days post wounding (G4) showing, strong positive cytoplasmic immunoreaction for VEGF in epidermis (arrow). [Avidin-biotin peroxidase stain with $\mathrm{Hx}$ counter stain $x 400$ ]
Fig.(4-C) A photomicrograph of a section in the skin of adult male albino rat 1day post wounding (G3) showing, moderate cytoplasmic immunoreaction for VEGF in epidermis (arrow). [Avidin-biotin peroxidase stain with $H x$ counter stain $x 400]$

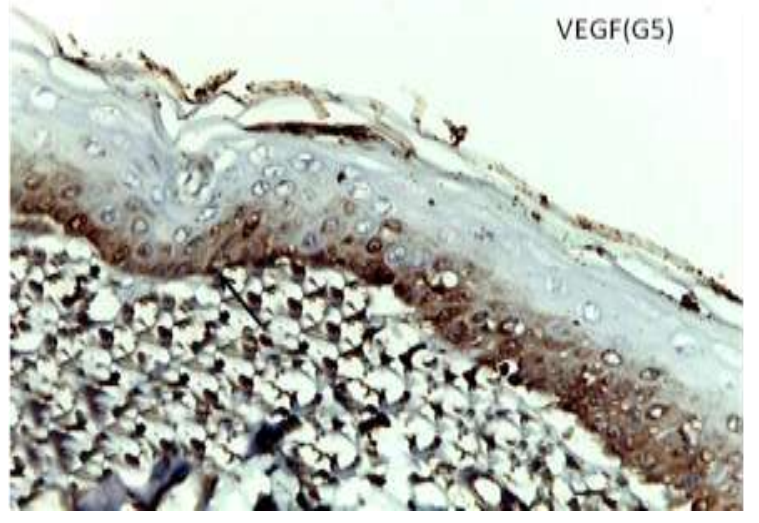

Fig.(4-E) A photomicrograph of a skin section of adult male albino rat, 6 days post wounding (G5) showing, strong positive cytoplasmic immunoreaction for VEGF in epidermis (arrow). [Avidin-biotin peroxidase stain with $H x$ counter stain $x 400]$ 


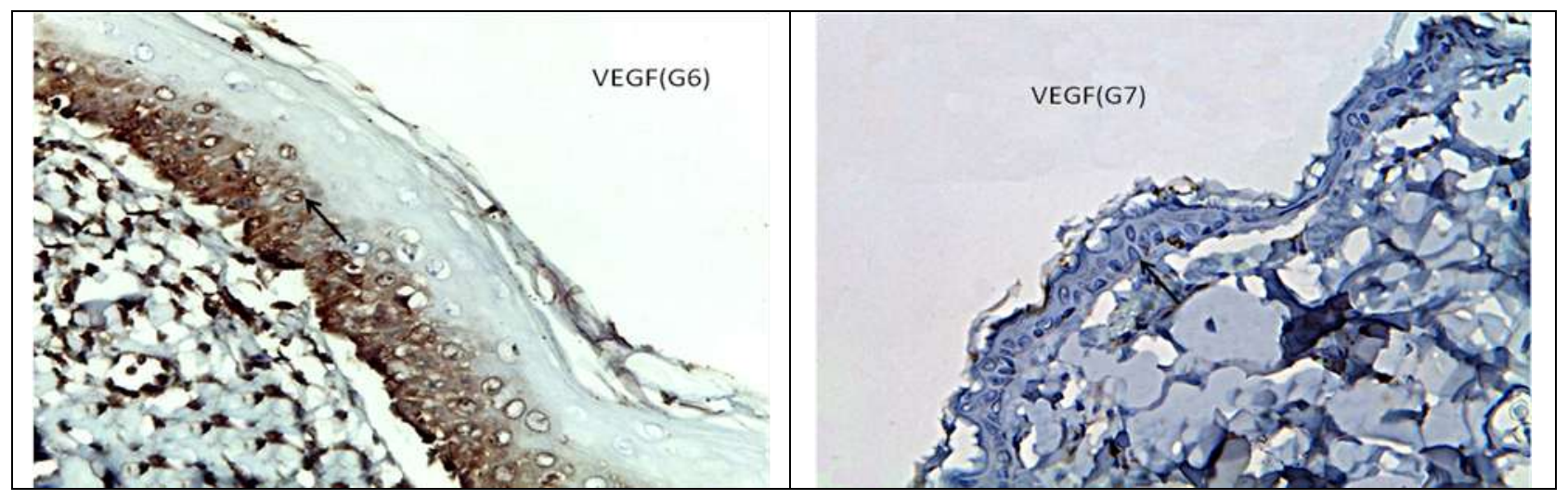

Fig.(4-F) A photomicrograph of a skin section of adult male albino rat 10 days post wounding (G6) showing, strong positive cytoplasmic immunoreaction for VEGF in epidermis (arrow) . [Avidin-biotin peroxidase stain with

Fig.(4-G) A photomicrograph of a skin section $\mathrm{P} / \mathrm{M}$ wound of adult male albino rat (G7) showing, negative immunoreactions for VEGF (arrow). [Avidin-biotin peroxidase stain with $H x$ counter stain $x 400]$ $H x$ counter stain $x 400$ ]

\section{DISCUSSION}

Chronological histopathological alterations characterizing the different phases of wound healing can be applied to wound age determination (Walcher, 1930 and Orsos, 1935). Wound healing is a highly coordinated process (Frank $\boldsymbol{e t}$ al., 1999). Wound repair (healing) is initiated with the aggregation of platelets, formation of a fibrin clot, and release of growth factors from the activated coagulation pathways, injured cells, platelets and extracellular matrix, followed by migration of inflammatory cells (including polymorph-nuclear cells, mononuclear cells and fibroblasts) to the wound site. Thereafter, keratinocytes migrate into the wound and angiogenesis is initiated. During the wound healing processes, an abundant blood supply is necessary to meet the enormous local demands of debridement, fibroblast proliferation, extracellular matrix synthesis and epithelialization (Riedel et al., 2005).

In the present study, 6 hours post wounding skin sections showed retraction of the two edges of the wound. This retraction might be occurred due to recoil of collagen and elastic fibers. Al-Henhena et al., (2011) stated that the wound contracture is a process that occurs throughout the healing process, increasing in the fibroblastic stage (proliferative phase) where the area of the wound undergoes shrinkage. Naked eye examination of wound in revealed that a blood clot covers the wound which may be detached during processing. The keratin scales covering the epidermis near the wound edge were fragmented. The epidermis appeared of irregular thickness. Collagen fibers in the dermis appeared distorted and discontinuous and the hair follicles were distorted in comparison to control. These findings were concomitant with Maderson \& Roth, (2005) who stated that, the epidermis on either side of the incision is affected along its length and the collagen fibers are destroyed with formation of blood clot covering the wound surface. 
One day post wounding skin sections in the current work revealed that the wound edges still retracted and surface of the wound was covered by a scap. The epithelial cells of the epidermis near wound edge appeared irregularly arranged with vacuolated cytoplasm and small darkly stained nuclei. The collagen fibers at the wound edge appeared coarse. Hair follicles at the wound edge appeared distorted compared with control. Mononuclear cellular infiltration could be observed. Braiman-Wiksman et al., (2007) and Ejaz et al., (2009) stated that wound healing is the natural process of regenerating dermal and epidermal tissue in body. During wound healing, a set of complex biochemical events take place. These events overlap in time and may be categorized into: the inflammatory, proliferative, and remodeling phases. In the inflammatory phase, bacteria and debris are phagocytosed and removed, and different factors are released, which cause the migration and division of cells involved in the proliferative phase. They also suggested that 1day post wounding corresponds to the inflammatory phase and includes blood clot formation. No re-epithelization or granulation tissue formation can be recorded. Also, new collagen fibers formation can't be detected.

Signs of wound healing could be detected 3days and 6days post wounding in the current study. A large scap covering wound surface could be detected. A newly formed epithelial layer (re-epithelization) began to appear 3days post wounding covered the wound surface 6days post wounding. This epithelium had variable thickness and flattening of dermo-epidermal junction. The epithelial cells appeared irregularly arranged, distorted with vacuolated cytoplasm and small, deeply stained nuclei. Granulation tissue filled the wound space. This granulation tissue was formed of mononuclear cellular infiltration, some newly formed collagen fibers and many dilated blood vessels (vascularization), 3days post wounding. 6days post wounding the cellular infiltration markedly increased. These findings were compatible with Braiman-Wiksman et al., (2007) who found that 3 to 7days post wounding, this period morphologically is marked by scab formation with migration of the epidermal edges (re-epithelization), proliferation of the granulation tissue and inflammatory response. Re-epithelialization is widely accepted to be one of the major processes in wound healing. Liang et al., (2012) stated that re-epithelization involves activation, migration and proliferation of keratinocytes from surrounding epidermis and adnexal structures (hair follicles). So, epithelialization during wound repair is mainly carried out by keratinocytes, which play an important role during this process. Gal et al., (2008) and Ejaz et al., (2009) said that the proliferative phase is characterized by angiogenesis, collagen deposition, granulation tissue formation and epithelization.

Epithelial tongues formed of aggregations of epithelial cells invading the dermis under the newly formed epithelium could be observed 3days and 6days post wounding. Ejaz et al., (2009) stated that re-epithelialization is accomplished by keratinocyte proliferation and migration over an extracellular matrix. Migrating epithelial cells intermingle with a matrix of fibrin crosslinked to fibronectin and collagen. Fibronectin enhances keratinocyte adhesion thus directing these cells to cross the wound base.

Ten days post wounding the scab was completely detached. Also, wound closure with a newly formed layer of epithelium could be observed. The epithelial cells appeared more or less normal. The dermo-epidermal junction was flattened with loss of the dermal papillae and skin appendages. The underlying granulation tissue was replaced by dermal tissue. This new dermis contained numerous blood vessels and mononuclear inflammatory cells (most probably fibroblasts and lymphocytes). These findings were supported by Braiman-Wiksman et al., (2007) who stated that 8-12days post wounding, scab detachment is observed. Histological 
results exhibit the formation of new epidermis. In addition, dermal closure is initiated concomitant to granulation tissue formation. Also, Alfars, (2009) supported our findings; he proved that the thickness of the newly formed epidermis was similar to intact epidermis during proliferative phase of wound healing. Typical histological picture of proliferative phase with new blood vessels could be detected.

As regard collagen fibers, there was increase in collagen fibers deposition, measured by morphometric study with increase wound age. This deposition was observed apparently 6days (G5) and 10days (G6) post wounding in which means of area \% of collagen fibers were 65.6 and 70.4 respectively. These findings were supported by (Kim et al., 2011) who stated that collagen synthesis was identified around wound 3days post wounding and increased at 5, 7days post wounding. In the present study, no obvious collagen fibers formation 6hours post wounding or in $\mathrm{P} / \mathrm{M}$ wound.

In the present work, numerous dilated blood vessels which were detected in granulation tissue of wound region 1day, 3days, 6days and 10days post wounding. Al-Henhena et al., (2011) stated that angiogenesis in granulation tissues improves circulation to the wound site thus providing oxygen and nutrients essential for the healing process that include-re-epithelization. This increase in vasculature might be related to VEGF which is a key regulator of cutaneous angiogenesis, and plays a role in several processes in the skin, including cancer development, psoriasis, and wound healing. During wound repair, VEGF is produced in abundance by keratinocytes in the skin. So, keratinocytes in the epidermis are thought to be the main source of VEGF during wound healing, but VEGF is also produced by dermal fibroblasts and macrophages in response to injury (Wilgus et al., 2005 and 2008).

VEGF expression was detected in the present study, 1day, 3days, 5days and 10days post wounding and this expression increased with increase post wounding date. The peak of the expression was demonstrated 10days post wounding. This increase in VEGF expression might be explained by increased demands to abundant blood supply during wound healing. Also, this expression mainly observed in keratinocytes of the epidermis in wound region. Hayashi et al., (2004) showed that the peak of VEGF expression was reached at a later phase of skin wound healing process, corresponding to the proliferative phase which histologically evidenced by angiogenesis and granulation tissue formation.

In the present work, VEGF was not expressed in normal skin, 6hours post wounding or P/M wound. Nissen et al., (1998) indicated that VEGF concentrations in surgical wound fluid were lowest on postoperative day 0 but increased steadily through postoperative day 7 . Takamiya et al. (2002) found that in cutaneous wounds, VEGF expression was detected in epidermal cells in 24 to 144 hours.

The present work revealed that iNOS was expressed in normal unwounded intact skin. These finding was supported by Frank et al. (1999) who stated that the iNOS is involved in many normal physiological conditions of the skin. In this study, iNOS expression could be detected in all $\mathrm{A} / \mathrm{M}$ groups while in $\mathrm{P} / \mathrm{M}$ iNOS expression was negative. The peak of iNOS expression was at 1 day and 10 days post wounding. This expression could be detected mainly in epidermal cells and in hair follicles cells. These findings were supported by Lee $\boldsymbol{e t}$ al., (2001) who found that, iNOS expression was detectable in wound region on days 1 and 3 after wounding, with sustained production up to 10 days after wounding. Also, (Zhao et al., 2005 \& 
2009) approved that iNOS was expressed in epidermis, hair follicle and sebaceous gland, it was expressed at 3hours, 6hours and 24hours post wounding but peaked at 1day and 10 day.

On the other hand, (Albina et al., 1990; Nill et al., 1995 and Frank et al., 1998) stated that, in rat wound healing, the highest iNOS expression was found between 6 and 24 hours and persisted between 1 and 5 days, then slowly decreased over the next 10 days. Lakshmi et al., (2011) reported that, the expression of iNOS in human burn wound was greater in day 3; it was almost similar in the initial days of healing. However, the expression was reduced on day 6. On day 15 there was no iNOS expression in the wound.

As regard, the inflammatory cells (cellular infiltrations) which were detected in the wound region from 1day post wounding in this study might be related to iNOS expression. Efron et al. (1999) suggested that, iNOS expression was induced during wound healing. Maximal iNOS expression on day 1 with decreased levels on days 3 and 5, it is present through all phases of healing but is maximal through the inflammatory phase. So, it has been shown that most NO synthesis is caused by the inflammatory cells present during early healing phases. However many cells, such as fibroblasts, participate in NO synthesis during the proliferative phase after wounding. Therefore, it is believed that iNOS activity can be down-regulated by the resolution of the inflammatory response or by cytokine signaling (Reichner et al., 1999 and Witte \& Barbul, 2002).

On the other hand, Gregory et al. (1991) stated that the inflammatory cells produce transforming growth factor-[beta], which causes the increase in VEGF mRNA levels. So, VEGF expression is associated with the inflammatory cells infiltration of dermal wound healing and it may be reasonable to suggest that these cells provoked dermal VEGF production. Also, Nogami et al. (2007) found that mRNA for VEGF is statistically significantly increased in the wound area in the tissue 1 day after the skin incision. The VEGF protein content in the wound tissue is statistically significantly high in the wound at 1 and 3 days after skin incision. These results indicate that VEGF is produced by inflammatory cells to induce vascularization in the early stage of the wound healing process.

Statistical study in the present work revealed that there was a highly significant statistical correlation between optical density means of iNOS and VEGF. Also, iNOS expressed in normal skin while VEGF was not expressed in normal skin. These findings might be attributed to a potent link between iNOS and VEGF expression which is proved by (Frank $\boldsymbol{e t}$ al., 1999) who stated that, during wound repair, iNOS-derived NO might activate or modulate gene transcription in target cells lying within the wounded tissue. They also demonstrated the potency of NO to regulate VEGF gene expression in human glioblastoma and hepatocarcinoma cells and rat renal mesangial cells. NO represents a potent inducer of VEGF expression. They added that reduced levels of VEGF mRNA are directly associated with the inhibition of iNOS activity during repair, suggesting that up-regulation of VEGF expression is dependent on the presence of a functionally active iNOS and hence, the availability of NO during normal wound healing. iNOs could be considered as a potential therapeutic target molecule to improve wound healing disorders.

As regard the statistical correlation between VEGF and collagen fibers formation, the present study approved that there was highly significant statistical correlation between VEGF optical density mean and mean area \% of collagen fibers. This was in concordance with (Wilgus et al., 2008) who stated that VEGF acts as link between angiogenesis and scar formation by directly stimulating both endothelial cells and dermal fibroblasts. These results make a link 
between angiogenesis and scarring supported by other models including lung fibrosis and liver fibrosis. Further studies will have to be done to assess potential clinical uses for VEGF neutralization in limiting scar formation or managing more severe fibrotic diseases.

In this study, naked eye examination of $\mathrm{P} / \mathrm{M}$ wound showed that no bleeding or clot formation which is most probably due to stop of blood circulation. Histological examination of $H \& E$ stained sections revealed that the signs of wound healing were absent at the wound region. Some collagen fibers and hair follicles appeared distorted due to early P/M autolytic changes. The findings of Obac et al. (2011) supported these findings, they stated that vitality or signs of wound healing are absent in post mortem wound. Also, no fibrin accumulation in the borders of the incision after death. In the present study, iNOS and VEGF were negative in P/M specimens. These results were in agreement with Takamiya et al. (2002) who revealed that there was no expression of VEGF in postmortem incisions.

In conclusion, histological changes during wound healing process could be assisted by immunohistological study for wound age estimation. iNOS expression peaked at 1day and 10days post wounding while, VEGF expression peaked at 10days post wounding. Neither iNOS nor VEGF was expressed in P/M wound. So, the time-dependent expressions of both VEGF, iNOS protein and area \% of collagen fibers during skin incised wound healing may be used as markers for wound age estimation. It is useful to use these markers as a complementary to each other to estimate wound age. However, further investigations using human wounded skin are necessary.

\section{REFERENCES}

Albina, J.E.; Mills, C.D.; Henry, J.R.W.L. (1990): Temporal expression of different pathways of L-arginine metabolism in healing wound. J Immunol, 144: 3877-80.

Alfars, A. A. (2009): Histological study of early events during wound healing in rabbits. Bas.J.Vet.Res., 8 (1):130-137.

Al-Henhena, N.; Mahmood, A. A.; Al-magrami, A.; Nor Syuhada, A. B.; Zahra،A. A.; Summaya, M. D.; Suzi, M. S. and Salmah, I. (2011): Histological study of wound healing potential by ethanol leaf extract of Strobilanthes crispus in rats. Journal of Medicinal Plants Research, 5 (16): 3660-3666.

Bancroft, J.D. and Gamble, M. (2002): Theory and practice of histological techniques. $5^{\text {th }}$ ed. Churchill Livingstone. Edinburgh and London.

Berg, S. and Bonte, W. (1971): Practical experience with the biochemical wound age determination. Beitr Gerichtl Med, 28:108-14.

Boissel, J.; Ohly, D.; Bros, M.; Godtel-Armbrust, U.; Forstermann, U. and Frank, S. (2004): The Neuronal Nitric Oxide Synthase Is Upregulated in Mouse Skin Repair and in Response to Epidermal Growth Factor in Human HaCaT Keratinocytes. Journal of Investigative Dermatology, 123: 132-139.

Braiman-Wiksman, L.; Solomonik, I.; Spira, R. and Tennenbaum, T. (2007): Novel Insights into Wound Healing Sequence of Events. Toxicologic Pathology, 35:767-779. 
Desmouliere, A.; Chaponnier, C.; Gabbiani, G. (2005): Tissue repair, contraction and the myofibroblast. Wound Repair Regen, 13(1):7-12.

Dressler, J.; Busuttil, A. and Koch, R. (2001): Sequence of melanocyte migration into human scar tissue. Int J Legal Med, 115:61-63.

Drury, R.A. and Wallington, E.A. (1980): Carleton's Histological Techniques. $5^{\text {th }}$ ed. Oxford University Press, Oxford, New York and Toronto, 144-45, 183-85.

Efron, D.T.; Thornton, F.J.; Steulten, C.; Tantry, U.S.; Witte, M.B.; Kiyama. T. and Barbul, A. (1999): Expression and function of inducible nitric oxide synthase during rat colon anastomotic healing, 3(6):592-601.

Eisenmenger, W.; Nerlich, A. and Glück, D. (1988): The meaning of collagen in wound age determination. Z Rechtsmed, 100:79-100.

Ejaz, S.; Ashraf, M.; Nawaz, M. and Lim, C.W. (2009): Total Particulate Matter and Wound Healing: An in vivo Study with Histological Insights. Biomedical and Environmental Sciences, 22: 278-287.

Frank, S.; Madlener, M. and Pfeilschifter, J. (1998): Induction of inducible nitric oxide synthase and its corresponding tetrahydrobiopterin-cofactor-synthesizing enzymeGTP-cyclohydrolase 1 during cutaneous wound repair. J Invest Dermatol, $111: 1058-64$.

Frank, S.; Stallmeyer, B.; Mpfer, H.K.; Kolb, N. and Schifter, J.P. (1999): Nitric oxide triggers enhanced induction of vascular endothelial growth factor expression in cultured keratinocytes (HaCaT) and during cutaneous wound repair. FASEB J., 13: 20022014.

Gal, P.; Kilik, R.; Mokry, M.; Vidinsky, B.; Vasilenko, T.; Mozes, S.; Bobrov, N.; Tomori, z.; Bober, J. and Lenhardt, L. (2008): Simple method of open skin wound healing model in corticosteroid-treated and diabetic rats: standardization of semiquantitative and quantitative histological assessments. Veterinarni Medicina, 53, (12): 652-659.

Gregory, J.; Dolecki, G.J. and Connolly, D.T. (1991): Effects of a variety of cytokines and inducing agents on vascular permeability factor mRNA levels in U937 cells. Biochem Biophys Res Commun, 180: 572-8.

Hayashi, T.; Ishida, Y.; Kimura, A.; Takayasu, T.; Eisenmenger, W. and Kondo, T. (2004): Forensic application of VEGF expression to skin wound age determination. Int $\mathbf{J}$ Legal Med, 118:320-325.

Iijima, K.; Yoshikawa, N. and Nakamura, H. (1996): Activation-induced expression of vascular permeability factor by human peripheral $\mathrm{T}$ cells: a non-radioisotopic semiquantitative reverse transcriptionpolymerase chain reaction assay. Journal of Immunological Methods, 196: 199-209.

Ishida, Y.; Kondo, T.; Takayasu, T.; Iwakura, Y. and Mukaida, N. (2004): The essential involvement of cross-talk between IFN-g and TGF-b in the skin wound-healing process. J Immunol, 172:1848-1855. 
Ishida, Y.; Kondo, T.; Kimura, A.; Matsushima, K. and Mukaida, N. (2006): Absence of IL-1 receptor antagonist impaired wound healing along with aberrant NF- $\mathrm{BB}$ activation and a reciprocal suppression of TGF- $\beta$ signal pathway. J Immunol, 176:5598-5606.

Ishida, Y.; Gao, J.L.; Murphy, P.M. (2008): Chemokine receptor CX3CR1 mediates skin wound healing by promoting macrophage and fibroblast accumulation and function. J Immunol, 180:569-579.

Kim, Y. S.; Cho, I.; Jeong, M.; Jeong, S.; Nah, S. Y.; Cho, Y.; Kim, S. H.; Go, A.; Kim, S. E.; Kang, S. S.; Moon, C. J.; Kim, J. C.; Kim, S. H. and Bae, C. S. (2011): Therapeutic effect of total ginseng saponin on skin wound healing. J Ginseng Res., 35 (3): 360-367.

Kondo, T.; Ohshima, T.; Mori, R.; Guan, D.W.; Ohshima, K. and Eisenmenger, W. (2002): Immunohistochemical detection of chemokines in human skin wounds and its application to wound age determination. Int J Legal Med, 116:87-91.

Kondo, T. (2007): Timing of skin wounds. Leg Med, 9:109-114.

Lakshmi, R.T.S.; Priyanka, T.; Meenakshi, J.; Mathangi, K.R.; Jeyaraman, V. and Babu, M. (2011): Low molecular weight heparin mediated regulation of nitric oxide synthase during burn wound healing. Ann Burns Fire Disasters, 24(1): 24-29.

Lee, R.H.; David, D.; Tantry, U. and Barbul, A. (2001): Nitric Oxide in the Healing Wound: A Time-Course Study. Journal of Surgical Research, 101: 104-108

Liang, x.; Bhattacharya, S.; Bajaj, G.; Guha, G.; Wang, Z.; Jang, H.; Leid, M.; Indra, A. K. and Ganguli-Indra, G. (2012): Delayed Cutaneous Wound Healing and Aberrant Expression of Hair Follicle Stem Cell Markers in Mice Selectively Lacking Ctip2 in Epidermis. PLoS ONE, 7 (2): 1-15.

Lin, Z. Q.; Kondo, T.; Ishida,Y.; Takayasu, T. and Mukaida, N. (2003): Essential involvement of IL-6 in the skin wound-healing process as evidenced by delayed wound healing in IL-6-deficient mice. J Leukoc Biol, 73, 713-21.

Maderson, P. F. A. and Roth, S. I. (2005): A histological study of the early stages of cutaneous wound healing in lizards in in vivo and in vitro. Journal of Experimental Zoology, 180 (2): 172-185.

Mohamad, H. E.; Askar, M. E. and Hafez, M. M. (2011): Management of cardiac fibrosis in diabetic rats; the role of peroxisome proliferator activated receptor gamma (PPARgamma) and calcium channel blockers (CCBs). Diabetology and metabolic syndrome, 3 (4): 1-12.

Mori, K.; Gehlbach, P.; Ando, A.; McVey, D.; Wei, L. and Campochiaro, P.A. (2002): Regression of ocular neovascularization in response to increased expression of pigment epithelium-derived factor. Invest Ophthalmol. Vis. Sci., 43, 2428-2434.

Nill, M.R.; Oberyszyn, T.M. and Ross, M.S. (1995): Quantification of inducible nitric oxide gene expression during incisional wound healing. Surg Forum, 46:753-5.

Nissen, N.N.; Polverini, P.J.; Koch, A.E.; Volin, M.V.; Gamelli, R.L. and Di- Pietro, L.A. (1998): Vascular endothelial growth factor mediates angiogenic activity during the proliferative phase of wound healing. Am J Pathol, 152:1445-1452 
Nogami, M.; Hoshi, T.; Kinoshita, M.; Arai, T.; Takama, M. and Takahashi, I. (2007): Vascular endothelial growth factor expression in rat skin incision wound. Med Mol Morphol, 40:82-87.

Nogami, M.; Hoshi, T.; Toukairin, Y. and Arai, T. (2010): Vascular endothelial growth factor in the early stage of skin incision wounds in cyclophosphamide-induced leukocytopenic rats. Legal Medicine, 12 (3): 128-131.

Obac, A. R.; Carvalho, E. G.; Silva, P.C.S.; Fenerich-Verani, N. and Almeida, M. (2011): Histological analysis of short-term vital reactions in skin wounds: potential applications in forensic work. Braz. J. Biol., 71 (4).

Oehmichen, M. (1990): Immunohistochemical techniques a new field of wound age investigation by forensic pathologists In: The wound healing. Berlin: Springer; Heidelberg New York, pp 5-67.

Orsos, F. (1935): Die vitalen Reaktionen und ihre gerichtsmedizinische Bedeutung. Beitr Pathol Anat, 95:163-241.

Ptilovanciv, E.O.; Fernandes, G.S.; Teixeira, L.C.; Reis, L.A.; Pessoa, E.A.; Convento, M.B.; Simoes, M.J.; Albertoni, G.A.; Schor, N. and Borges, F.T. (2013): Heme oxygenase 1 improves glucoses metabolism and kidney histological alterations in diabetic rats. Diabetol Metab Syndr., 5: 3.

Raekallio, J. (1976): Timing of wounds in forensic medicine. Jpn J Legal Med, 30:125-36.

Reichner, J.S.; Meszaros, A.J. and Louis, C.A. (1999): Molecular and metabolic evidence for the restricted expression of inducible nitric oxide synthase in healing wounds. Am J Pathol, 154:1097-104.

Riedel,F.; Philipp, K.; Sadick, H.; Goessler, U.; Hormann, K. and Verse, T. (2005): Immunohistochemical Analysis of Radiation-induced Non-healing Dermal Wounds of the Head and Neck. In vivo, 19: 343-350.

Sato, Y.; Ohshima, T. and Kondo, T. (1999): Regulatory role of endogeneous interleukin-10 in cutaneous inflammatory response of murine wound healing. Biochem Biophys Res Commun, 265: 194-199.

Sato, Y. and Ohshima, T. (2000): The expression of mRNA of proinflammatory cytokines during skin wound healing in mice: a preliminary study for forensic wound age estimation. Int J Legal Med, 113:140-145.

Takamiya, M.; Saigusa, K. and Aoki, Y. (2002): Immunohistochemical study of basic fibroblast growth factor and vascular endothelial growth factor expression for age determination of cutaneous wounds. Am J Forensic Med Pathol, 23:264-7.

Tao, X.; Huang, Y. and Li, R. (2007): Assessment of local angiogenesis and vascular endothelial growth factor in the patients with atrophic-erosive and reticular oral lichen planus. Oral Surg Oral Med Oral Pathol Oral Radiol Endod, 103: 661-669.

Walcher, K. U. (1930): About vital reaction. Dtsch Z Gesamte Gerichtl Med, 15:16-57. (Quoted from Kondo, 2007). 
Wang, J.R.; Zhou, Y.; Sang, K. and Li, q. (2013): Association between pulmonary vascular remodeling and expression of hypoxia-inducible factor-1 $\alpha$, endothelin-1 and inducible nitric oxide synthase in pulmonary vessels in neonatal rats with hypoxic pulmonary hypertension. Zhongguo Dang Dai Er Ke Za Zhi., 15(2):138-44.

Wilgus, T.A.; Matthies, A.M.; Radek, K.A.; Dovi, J.V.; Burns, A.L.; Shankar, R. and Dipietro, L.A. (2005): Novel Function for Vascular Endothelial Growth Factor Receptor-1 on Epidermal Keratinocytes. Am J Pathol., 167(5): 1257-1266.

Wilgus, T.A.; Ferreira, A.M.; Oberyszyn, T.M.; Bergdall, V.K. and Dipietro, L.A. (2008): Regulation of scar formation by vascular endothelial growth factor. Lab. Invest. , 88(6): 579-590.

Witte, M.B and Barbul, A. (2002): Role of nitric oxide in wound repair. Am J Surg, 183:40612.

Zhao, R.; Guan, D.W. and Lu, B. (2005): Immunohistochemical study on expression of iNOS and eNOS during skin incised wound healing in mice. Fa Yi Xue Za Zhi, 21(3):161-4.

Zhao, R.; Guan, D.; Zhang, W.;Du, Y.; Xiong, C.; Zhu, B. and Zhang, J. (2009): Increased expressions and activations of apoptosis-related factors in cell signaling during incised skin wound healing in mice: A preliminary study for forensic wound age estimation. Legal Medicine, 11: 155-160.

Zhuang, P.; Shen, J.; Zhu, X.; Lu, L.; Wang, L.; Tang, Z. and Sun, H. (2013): Prognostic Roles of Cross-Talk between Peritumoral Hepatocytes and Stromal Cells in Hepatocellular Carcinoma Involving Peritumoral VEGF-C, VEGFR-1 and VEGFR3. PLoS One, 8(5): 1-11. 


\section{دراسة هستولوجية وهستوكيميائية مناعية لكل من المحرض سينسيز اكسيد النيتريك و عامل نمو بطانة

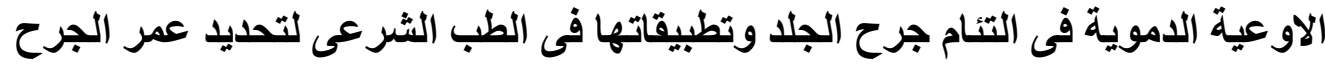

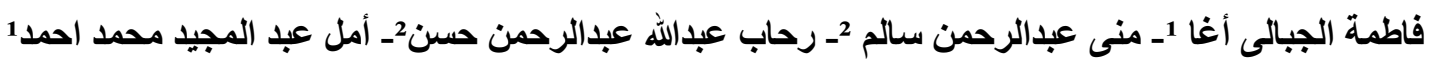 1 قسم الطب الثر عى و السموم الإكلنيكية ـ2 قسم الهستولوجيا (كلية طب البناتـ جامعة الأزهر )}

فحص التئام الجروح لتقدير عمر الجرح هو احد اهم الجوانب فى الطب الثرعى. وتميز التغييرات الهستولوجية

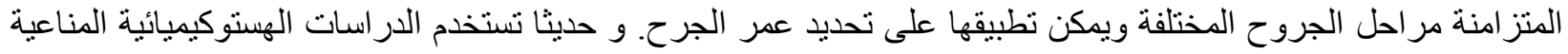

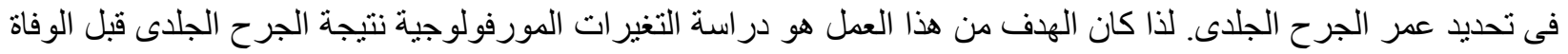

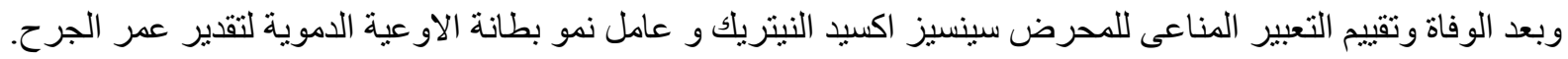

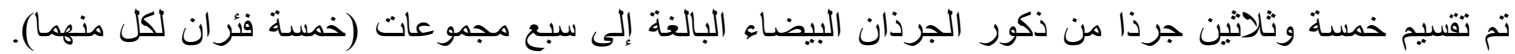

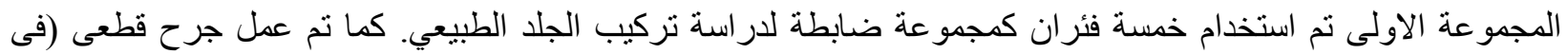

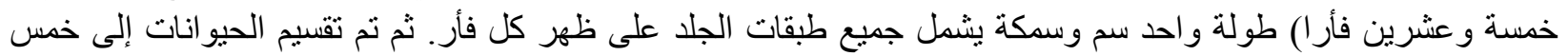

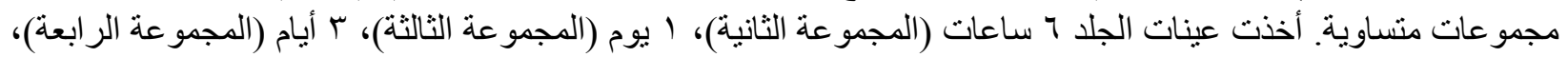

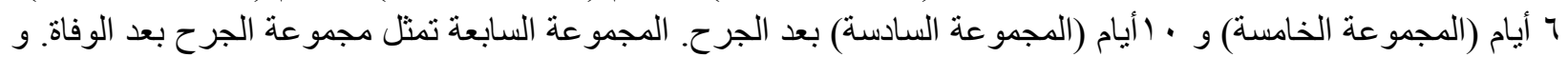

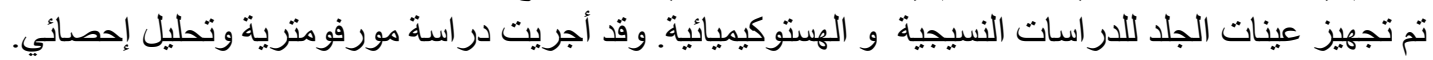

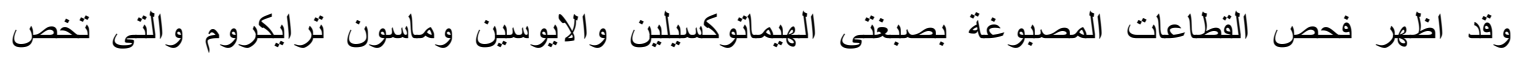

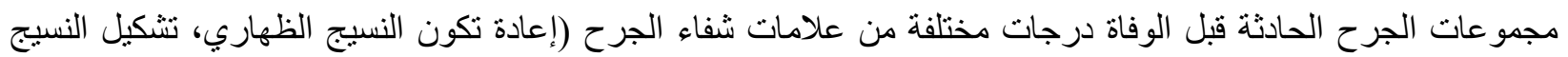

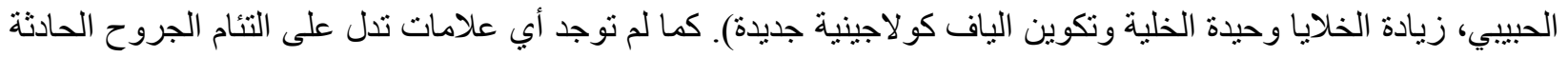

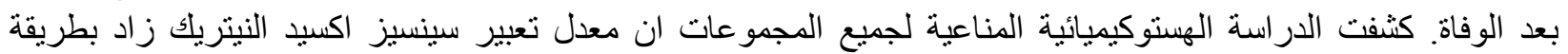

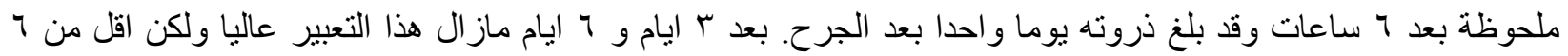

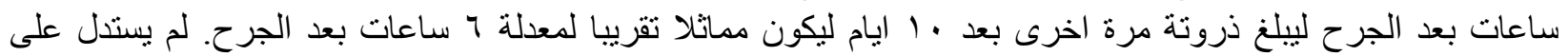

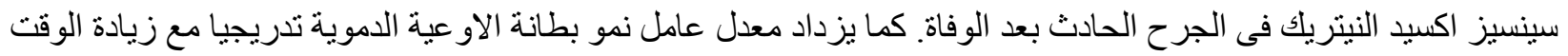

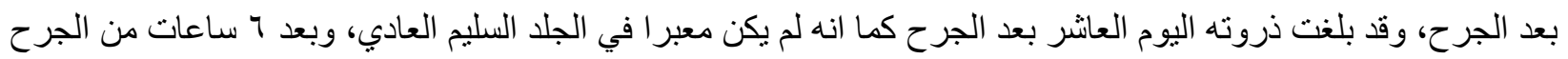

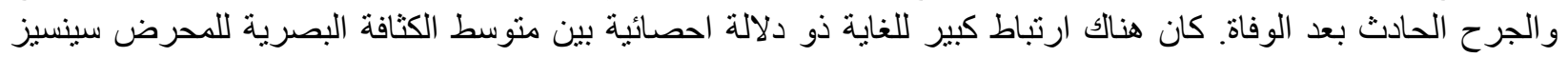

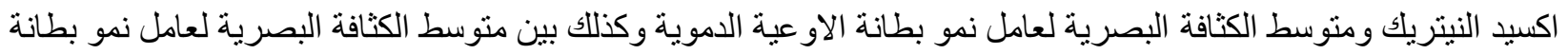

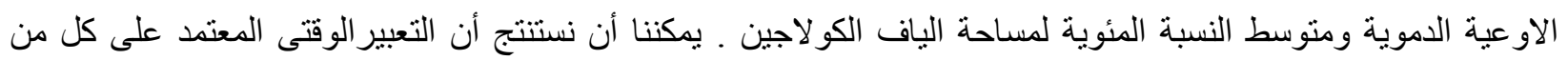

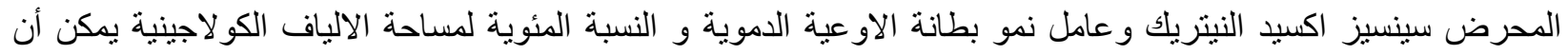
تكون علامات مفيدة لتحديد سن الجرح الجلدي مع مساعده التغيير ات الهستولوجية خلال مر احل التهل التئام الجرح. 